\title{
Responding to salinity in a rural African alluvial valley aquifer system: to boldly go beyond the world of hand-pumped groundwater supply?
}

\author{
Michael O. Rivett ${ }^{1, *}$, Laura Budimir ${ }^{1}$, Nicholas Mannix ${ }^{1}$, Alexandra V.M. Miller ${ }^{1}$, Marc Addison ${ }^{1}$, \\ Phideria Moyo ${ }^{2}$, Gift J. Wanangwa², Owen L. Phiri², Chrispine E. Songola ${ }^{3}$, Muthi Nhlema ${ }^{4}$, \\ Mavuto A.S. Thomas ${ }^{5}$, Reid T. Polmanteer ${ }^{1,6}$, Amando Borge ${ }^{1}$, Robert M. Kalin ${ }^{1}$
}

This manuscript version is the "Accepted Author Manuscript" - the final published article may be accessed via the DOI link in the citation below:

Rivett, M.O., Budimir, L., Mannix, N., Addison, M., Miller, A.V.M., Addison, M., Moyo, P., Wanangwa, G.J., Phiri, O.L., Songola, C.E., Nhlema, M., Thomas, M.A.S., Polmanteer, R.T., Borge, A., Kalin, R.M., 2018. Responding to salinity in a rural African alluvial valley aquifer system: to boldly go beyond the world of hand-pumped groundwater supply? Science of the Total Environment, XX, XXX-XXX. https://doi.org/ >>>

\section{Graphical abstract}

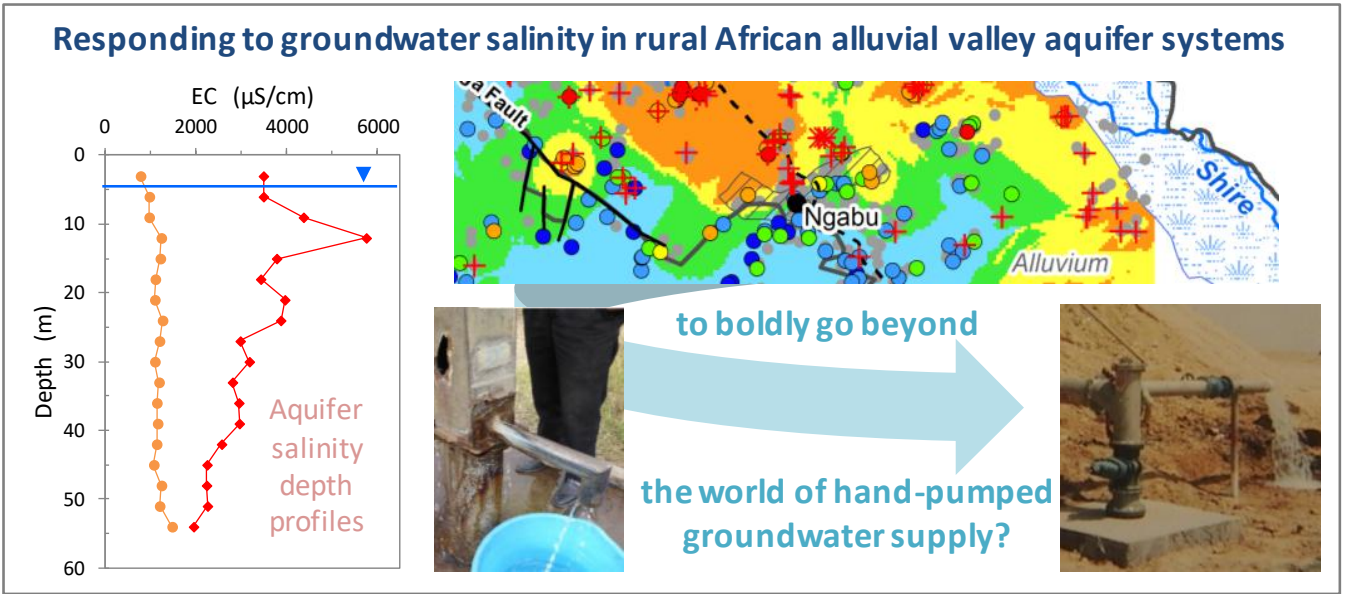

\section{Highlights}

- Effective response to developing-world groundwater salinity to safeguard water supply

- $\quad$ Salinity problem defined via conceptual model - salinity survey - water-point mapping

- Groundwater salinity response capacity constrained in Malawi by multiple factors

- Need to evaluate options beyond model-supply paradigm of hand-pumped borehole supply

- Feasibility study of larger groundwater or surface-water supply alternatives 


\section{Responding to salinity in a rural African alluvial valley aquifer system: to}

\section{boldly go beyond the world of hand-pumped groundwater supply?}

Michael O. Rivett ${ }^{1, *}$, Laura Budimir ${ }^{1}$, Nicholas Mannix ${ }^{1}$, Alexandra V.M. Miller ${ }^{1}$, Marc Addison $^{1}$, Phideria Moyo ${ }^{2}$, Gift J. Wanangwa ${ }^{2}$, Owen L. Phiri ${ }^{2}$, Chrispine E. Songola ${ }^{3}$, Muthi Nhlema ${ }^{4}$, Mavuto A.S. Thomas ${ }^{5}$, Reid T. Polmanteer ${ }^{1,6}$, Amando Borge ${ }^{1}$, Robert M. Kalin ${ }^{1}$

${ }^{1}$ Department of Civil and Environmental Engineering, University of Strathclyde, Glasgow G1 1XJ, UK

${ }^{2}$ The Ministry of Agriculture, Irrigation and Water Development, Regional Irrigation and Water Development Office - South, Private Bag 13, Blantyre, Malawi

${ }^{3}$ District Water Development Office Chikwawa District Council, Private Bag 1, Chikwawa, Malawi

${ }^{4}$ BASEflow, Galaxy House, Blantyre, Malawi.

${ }^{5}$ Dowa District Health Office, P.O. Box 25, Dowa, Malawi (formerly Chikwawa District Health Office).

${ }^{6}$ Now at: HRS Water Consultants, Lakewood, CO 80215, USA

* Corresponding author at: Department of Civil and Environmental Engineering, University of Strathclyde, Glasgow G1 1XJ, UK.

E-mail address: Michael.Rivett@strath.ac.uk (M.O. Rivett). 
Abstract

Effective response to groundwater salinity in the developing world may critically safeguard drinking-water supplies. Groundwater resources throughout rural Africa are exploited by a vast and increasing number of hand-pumped boreholes for community supply. Our research in TA Ngabu (Shire Valley), Southern Malawi aims to: define groundwater-salinity problem occurrence within its semi-arid alluvial-valley aquifer setting and rural developing-world context; critique current capacity to respond; and, to discuss future response options - in particular considering the need to explore alternative options that boldly go beyond the world of hand-pumped groundwater supply. Salinity problem definition was achieved through survey of 419 hand-pumped boreholes that revealed widespread brackish groundwater causing nonpotable (unpalatable) drinking-water supplies. Persistent non-functionality or abandonment of boreholes was typically ascribed to salinity. Whilst salinity is conceptualised to arise from shallow-groundwater evaporation, formation-evaporite dissolution and faulted-area upwelling, sparse data locally renders attribution of salinity sources to individual boreholes difficult. There is a significant need to better resolve the vertical distribution of salinity. Problem response capacity was hampered by multiple factors, including, sector inertia, low drilling costs compromising water-point integrity, and lack of technical vision for alternatives. Various recommendations are made to improve response capacity continuing to work at the hand-pump supply scale. However, in areas where salinity is significant, exploring the feasibility of other options is advocated in conjunction with technical capacity development. Groundwater options may utilise high borehole yields possible from alluvial aquifers, grossly under-exploited by hand pumps. Groundwater at depth, albeit of unknown quality typically, or pipeline transfers of probable good-quality groundwater from valley-margin units, should be considered. Surface-water pipeline supplies may be viable for (growing) population centres. Canal-fed irrigation schemes (pending for the area), should be multiple-use, protective of groundwater and embrace pipeline drinking-water supply and managed-aquifer-recharge opportunities. Advancing desalination technologies, although presently unaffordable, should be kept under review.

Keywords: Salinity; Groundwater; Sustainable Development Goal (SDG) 6; Drinking water; Malawi; Alluvial aquifer

\section{Introduction}

Groundwater resource loss can be critical in semi-arid regions where surface waters may be non-existent, or ephemeral, and groundwater is hoped to provide year-round supply. This is especially true in rural sub-Saharan Africa (SSA) where populations frequently draw their water supply from hand-pumped boreholes operated under a community based management (CBM) model (Pavelic et al., 2012). Such supplies represent the model paradigm for rural water management across SSA and are central to continued efforts to meet Sustainable Development Goal 6 (SDG 6) (Carter, 2015; Chen et al., 2016; Hutchings et al., 2015). Some 1.2 billion people across SSA and South Asia have gained access to improved water sources between 1990 and 2015, with hand-pumped borehole supplies prominent in the increased 
access to safe water achieved under WaSH (water and sanitation hygiene) programmes (Howard et al., 2016; JMP, 2014).

Continued pressures to achieve ambitious water-supply coverage targets, however, may result in some water points being installed in less than ideal hydrogeological locations (Bonsor et al., 2015; MacDonald and Calow, 2009). Although availability of sufficient water volume can prove critical, a correctly installed borehole in even a relatively minor aquifer should supply the quite modest domestic - drinking-water hand-pump supply needs of a rural community. A more pervasive concern can be unacceptable water quality; in semi-arid areas, this could simply manifest as groundwater of elevated salinity. Salinity may render drinking water supplies nonpotable (unpalatable) (WHO, 2017), soils becoming salinized (Huang et al., 2016), reduced crop yields (Xue et al., 2018) and degraded ecosystems (Pisinaras et al., 2010). It could contribute to health impacts related to excess salt intake (Talukder et al., 2016; Vineis et al., 2011). Problems are not just restricted to the developing world; mounting pressures exist in the developed world to make greater use of brackish, moderate salinity, groundwater. In the USA, increasing efforts are now made to delineate brackish groundwater resources to strategically deploy desalination systems there to augment drinking-water supplies as freshwater sources become increasingly scarce (Chowdhury et al., 2018). Groundwater salinity is of mounting concern in many semi-arid systems globally (Boukhari et al., 2018; Liu et al., 2018), and may be increasingly exacerbated by the impacts of irrigated agriculture (Foster et al., 2018). Salinity within shallow or intermediate depth groundwater is considered high over $16 \%$ of the global land area, within which some 1.1 billion people reside (Van Weert et al., 2009). It is foremost in the basins of west and central Asia with occurrences documented across SSA (Van Weert et al., 2009). Salinity occurrence in SSA is, however, perceived far from fully documented due to the frequent sparseness of groundwater-quality data (MacDonald et al. 2012).

A complexity of processes may cause groundwater salinity related to marine, terrestrial or anthropogenic origins (Van Weert et al., 2009). These include natural rock weathering and dissolution of evaporite salts (halite, etc.), high rates of phreatic evaporation from current or historic shallow water tables, coastal saline intrusion, abstraction-induced up-coning of deeper saline fossil waters, deep-brine migration through fracture/fault conduits to shallow aquifers, groundwater irrigation of crops, flood inundation of lowlands and subsequent flushingevaporation cycles (intensified by climate change), and anthropogenic inputs (Abu-alnaeem, et al., 2018; Ali et al., 2002; Argamasilla et al., 2017; Back et al., 2018; Foster and Chilton, 2003; Greene et al., 2016; Pauwels et al., 2013; Rivett et al., 2016; Salameh et al., 2014; Van Weert et al., 2009). Many of these processes may contribute to groundwater salinity in semi-arid lowland valley alluvial-aquifer systems that form the focus of our research. Such systems are globally important to developing-world water supply.

Responding to groundwater salinity in the developing world is challenging. Many handpumped borehole supplies operate under a CBM model, a model that forms the dominant paradigm in SSA rural water management. Whilst CBM effectiveness may be questioned for many reasons (Van Den Broek and Brown, 2015), and there are recognised challenges to sustaining CBM at scale (Hutchins et al., 2015), our primary concern herein is the potential limited capacity of the pervasive CBM hand-pumped borehole-supply paradigm to allow 
strategic response to groundwater-salinity problems. This concern is fuelled by observations in our study area of many water points being installed in recent years by various organisations (NGO (non-governmental organisation), government, private) that have proven to be of elevated salinity. There appears little co-ordination of activities, or thought to strategically address the salinity problem at large. The unfortunate result is that communities make do with salty water, or walk long distances to a borehole of better water quality that may become over-subscribed. Or worse still, return to unimproved water sources with acute pathogen risks (Monjerezi et al., 2011a). Precedent for the development or rural community supply schemes that look beyond the CBM model paradigm of hand-pumped groundwater supply is set by the success of cases in India, for example, employing multi-village piped supply schemes (Hutchings et al., 2017).

Our research in the Traditional Authority (TA) Ngabu area within the Chikwawa District of Southern Malawi aims to: define the nature of the groundwater salinity problem occurring within the semi-arid, lowland alluvial-valley aquifer setting and, importantly, developing-world rural context; critique current capacity to respond to the conceptualised salinity problem; and, discuss, in outline, future response options possible. In that forward look, we critically question the need to explore alternative options that boldly go beyond the world of hand-pumped groundwater supply. Whilst an African case study, our expectation is it has resonance with similar problem scenarios across the developing world.

\section{Methods}

In overview, our approach was to: survey current groundwater salinity occurrence in Ngabu and evaluate constraints imposed upon drinking-water and irrigation supply; define the salinity problem through development of a processes-based conceptual model relevant to drinkingwater supply (drawing on review of the wider Chikwawa literature); to inform problem definition via consideration of contextual mapped water-point data on resource development, water-point functionality, population dependence, and salinity-problem awareness; and, critique, based on the first-hand and wide-ranging authorship experience, current Malawian capacity to respond to the salinity problem diagnosed.

\subsection{Study setting}

The TA Ngabu study area and wider Chikwawa District are located within the Lower Shire Valley (Fig. 1). The Shire River forms the sole outflow from Lake Malawi flowing south through the study area to the Zambezi River. Flow typically varies seasonally from around $400-1000$ $\mathrm{m}^{3} / \mathrm{s}$ in the study-area reach (MoAIWD, 2016a). Chikwawa, meaning 'flat valley', constitutes an archetypal rural African lowland, semi-arid, valley plain setting underlain by an alluvial valley aquifer, in turn, underlain by the pan-African Basement rock (Fig. 1). TA Ngabu covers an area of $1093 \mathrm{~km}^{2}$ with a population of 145,000 , one third of the Chikwawa District (National Statistical Office of Malawi, 2008). This predominantly rural population is sparsely distributed, averaging 132 people per $\mathrm{km}^{2}$ reaching up to $500-1500$ people per $\mathrm{km}^{2}$ in townships. 
a)

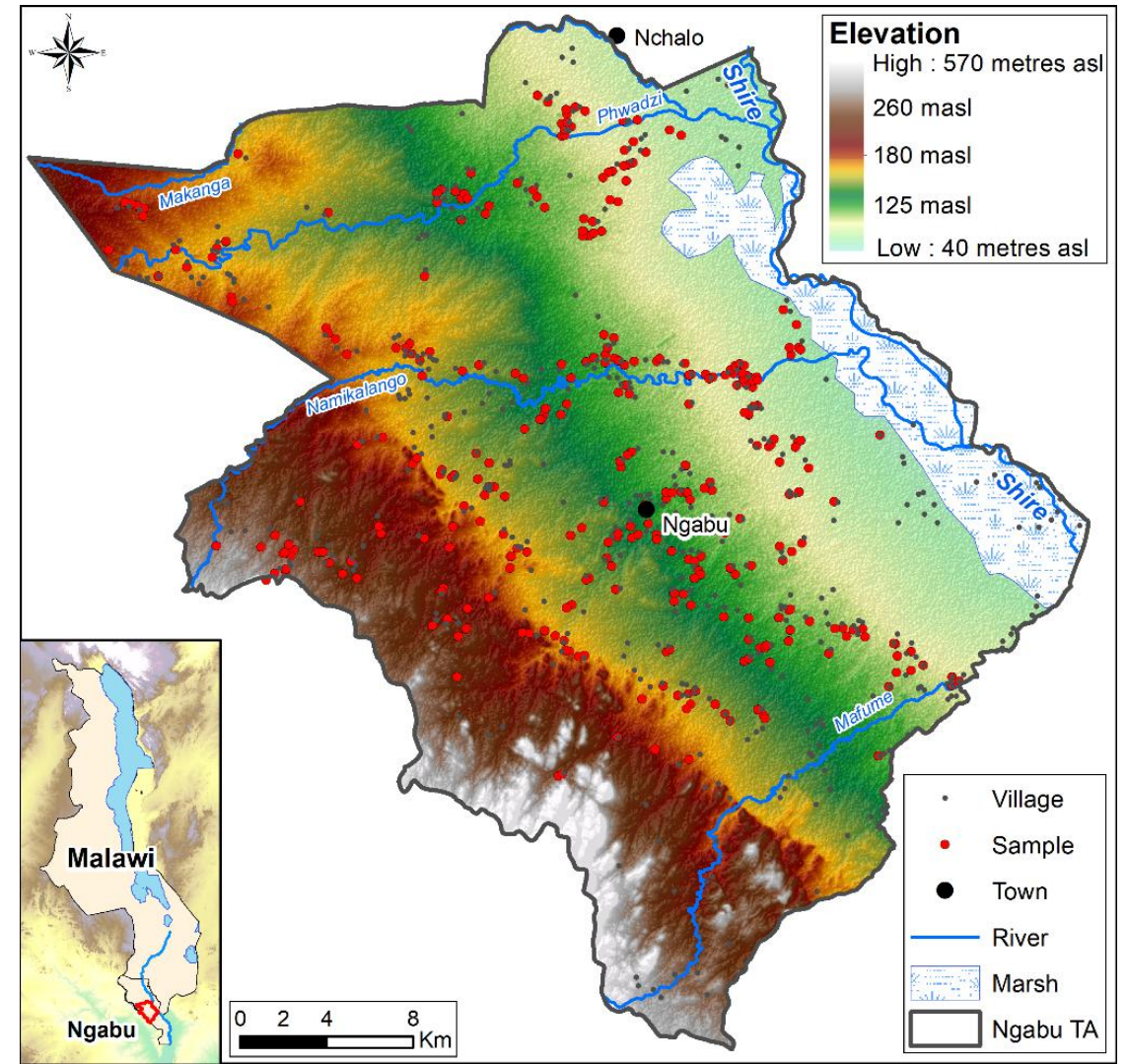

b)

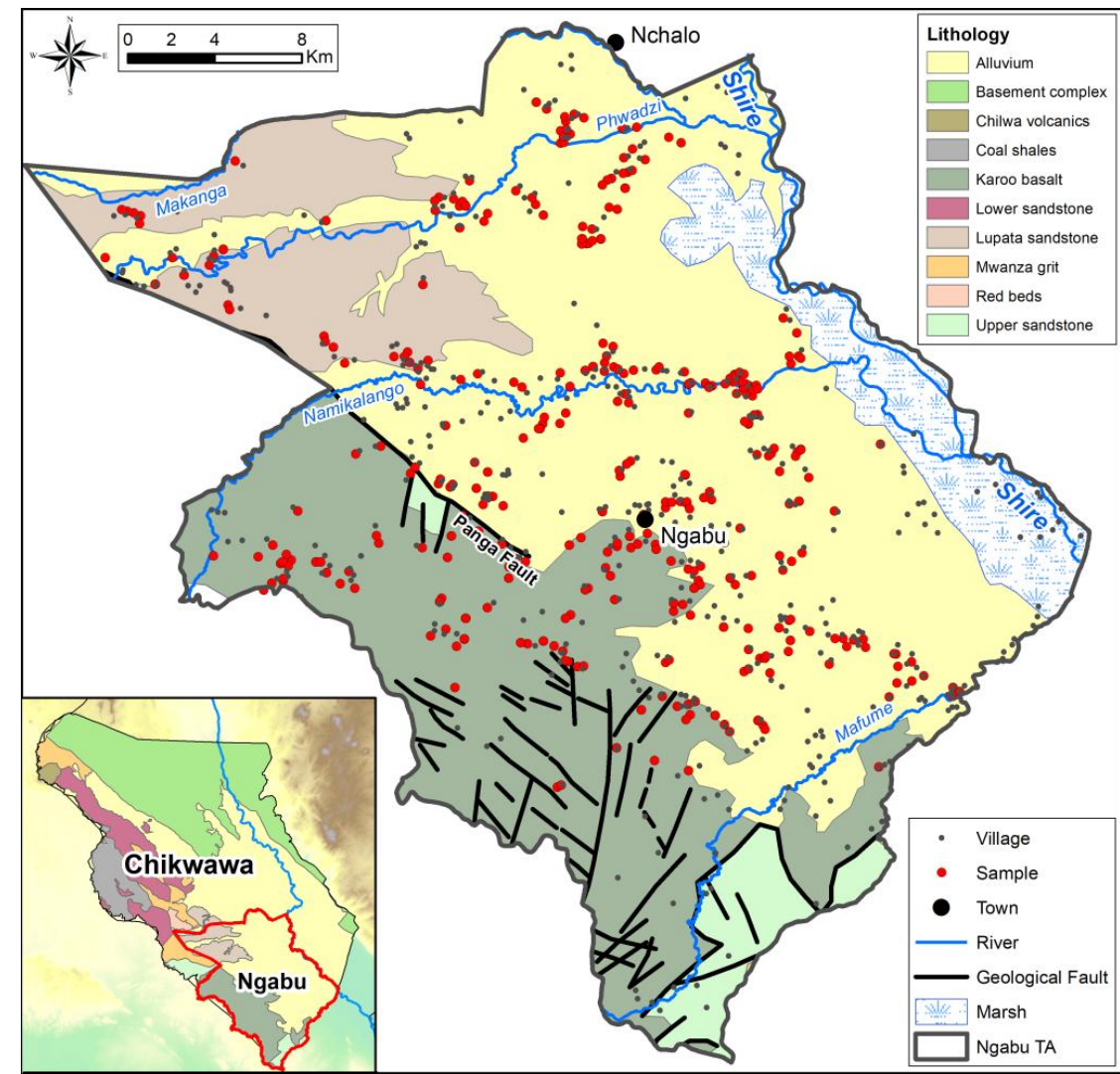

Fig. 1. The Ngabu Traditional Authority study area showing borehole water points sampled in the 2016 groundwater-quality survey relative to (a) topography in metres above sea level ( $m$ asl) and (b) geology (based on 1:250,000 geological map (1970) published by the Geological Survey of Malawi). 
TA Ngabu experiences some of Malawi's greatest climate variability (Joshua et al., 2016). It has the lowest rainfall within the Chikwawa District from c. $200 \mathrm{~mm}$ up to $950 \mathrm{~mm}$ per annum in wet years (Monjerezi, 2012; Sutcliffe, et al., 2016). Most precipitation (90\%) occurs between November and April (Ngongondo et al., 2011) causing vulnerability to both drought and flood. Food security is limited and aid often required (Ibrahim and Alex, 2008). The area is vulnerable to climate change expected to cause rising average temperatures, rainfall variability and reduced soil moisture (Burney et al., 2013; Coulibaly et al., 2015; Lobell et al., 2008). Ngabu is famous for its livestock and charcoal production, leading to overgrazing and deforestation concerns (MoAIWD, 2016a).

Malawi's geology is influenced by tectonics of the East African Rift (EAR) leading to high escarpments adjacent to low-lying basins (Castaing, 1991). Ngabu is characterised by four main series common across south-eastern Africa, the Precambrian Basement complex, the Karoo formation, the Cretaceous Lupata sandstone and unconsolidated Quaternary alluvium (Fig. 1; Upton et al., 2018). Basement rocks occur in the west, where the Panga escarpment and associated formations show evidence of faulting (Bennet, 1972). The Lupata sandstone and Karoo basalt outcrops form the western higher ground escarpment and underlie the valley floor depositional alluvium. The alluvial deposits of the Lower Shire Valley can be up to $150 \mathrm{~m}$ thick (Muir and Stephen, 1957; Smith-Carington and Chilton, 1983). Soils classified as being of the Makande Plain, are characterised by lithomorphic vertisols, shallow lithomorphic vertisols/lithosols and topovertisols. These contain clays and clayey loams formed from the basaltic rocks to the west. Alluvial calcimorphic soils that characterise areas towards the western bank of the Shire River are often saline and sodic in nature, attributed to high evaporation rates and soil capillary action (Monjerezi, 2012).

Groundwater forms Malawi's main potable water resource with sole reliance in most rural areas where $90 \%$ of its population resides (Mapoma and Xie, 2014; Upton et al., 2018). The alluvial aquifer forms the main groundwater resource in TA Ngabu. It has significantly greater storage and yield potential than the fractured/weathered Basement rock (Smith-Carington and Chilton 1983). Where the basement is highly faulted and fractured, to the north-west of the area, this too may serve as a valuable local resource (Robins et al., 2013). Where the basement or other underling units are transmissive and in hydraulic continuity, they may discharge significant groundwater to the adjoining shallow alluvial-aquifer resource. Groundwater generally flows from the higher recharge escarpment - plain margin areas across the valley plain towards the Shire River axis and southern marshland discharge areas (Fig. 1; Monjerezi et al., 2011a). Groundwater provides the area's dominant source of water supply for domestic, drinking and irrigation needs.

Groundwater salinity has been recognised to be an issue in Southern Malawi since the late 1960s (Bath, 1980; Bradford, 1973; Davis, 1969; Lockwood Survey Cooperation 1970). Even so, this has not inhibited widespread groundwater exploitation, predominantly via hand-pump borehole supplies driven by their low individual water point cost. Also, groundwater represents the most economic and often only option available in areas where other water supply options are not perceived viable (Smith-Carington and Chilton, 1983). Elevated 
groundwater salinity is, however, widespread and results in potability issues and borehole abandonment. Specific areas include the eastern Bwanje Valley (Pavelic, 2012), Lake Chilwa area (Bath, 1980), but, most notably, the Chikwawa District in the Lower Shire Basin (Monjerezi, 2012; Monjerezi et al., 2011a,b, 2012; Monjerezi and Ngongondo, 2012; Smith Carington and Chilton, 1983). Processes controlling salinity occurrence have been reviewed and are presented in summary within our conceptual model build (Section 3.4). Despite these many studies, routine network monitoring of groundwater quality and hence salinity, has unfortunately failed to substantially occur across Malawi (MoAIWD, 2017a; Rivett et al., 2018b).

\subsection{Groundwater-quality survey and supporting survey data}

\subsubsection{Supporting survey data: water-point mapping}

Our research forms part of the 'Climate Justice Fund: Water Futures Programme' (CJF) (www.cjfwaterfuturesprogramme.com) funded by the Scottish Government that aims to support the Government of Malawi in achieving SDG 6. Additional to the main groundwater quality survey conducted herein (see below), our interpretation draws upon CJF's recent water-point mapping of Southern Malawi that helps to fulfil Malawi's National Water Resources Master Plan (MoAIWD, 2017a). CJF's recently developed mWater online Management Information System (MIS) tool (www.mwater.co) for Malawi is used to access the significant volume of recently mapped water-point data obtained via site inspections and survey interview questionnaires (Miller et al., 2018). Mapped water points include any 'improved' water supply, hence not only boreholes, but also protected dug wells, piped supplies to communal taps (typically groundwater based) and protected springs. Data used herein from mWater include borehole location, water-point functional status, borehole depth, population numbers served, and user community survey responses identifying water points having current problems of 'poor water quality'. Survey data drawn upon were collected at various dates over 2016-18. Acknowledging the variation in functionality status definition (Bonsor et al., 2018; Carter and Ross, 2016), we adopt the mWater survey definition common across that MIS, used by (major) NGOs and others. A 'functional' water point is defined to be in good working condition and regularly provides water according to the specifications in the original design. A water point is defined as 'not functional' if it is no longer providing water on a regular basis - this could be due to maintenance issues, changes in water availability or quality (incl. salinity), or problems with access to the water point.

\subsubsection{Groundwater-quality survey}

Groundwater-quality survey samples were collected in 2016 from 419 existing community water supplies (all hand pumps) throughout TA Ngabu (Budimir, 2017; Fig. 1). It represents the most detailed survey of hand-pumped groundwater quality hitherto available for the area. These are not formal network monitoring points and locations chosen were dictated by surveying of the communities served rather than having a hydrogeological basis (although good coverage was still achieved in this regard). Samples were collected during the early dryseason period (May - early July) by the Malawi Ministry of Agriculture Irrigation and Water Development (MoAIWD) staff following procedures outlined in APHA (2005). All water points 
were in regular use by community users. Electrical conductivity (EC) was measured and samples collected and transported to the MoAIWD laboratory (Blantyre) for analysis.

The depths of sampled water points are largely unknown, but it is typical that boreholes are screened over a range of possible depths between $15 \mathrm{~m}$ to $50 \mathrm{~m}$. They will primarily sample the shallowest main aquifer resource intersected. This depth range estimate is based upon our own observations of recent drilling and historic borehole installation practices (Smith Carington and Chilton, 1983). Only 1.4\% of CJF mapped boreholes in the TA Ngabu study area had depth data collected; their depth range of 21-58 m nevertheless confirms above depth expectations. Such data scarcity precluded detailed depth analysis of survey-observed salinity, however, we do present CJF depth-profile data EC (electrical conductivity) obtained during drilling of boreholes outside the Ngabu study area (but still within the Chikwawa alluvial aquifer) that exemplify trends in aquifer salinity with depth (Polmanteer and Kalin, 2014).

Laboratory analysis in Malawi of hydrochemical parameters (major ions, iron and total dissolved solids (TDS)) used standard MoAIWD operating procedures based on APHA (2005). Whilst methods are considered reliable, most are dated in comparison to a modern laboratory. There is a pressing need for funding mechanisms to sustainably develop the Malawi Government MoAIWD's analytical laboratory capacity (MoAIWD, 2017a) and better underpin Malawian capacity to manage salinity. Bicarbonate and carbonate ions were analysed by standard alkalinity titration methods, chloride by silver nitrate titration, and calcium and magnesium were by EDTA titration, sulfate, nitrate and iron via UV spectrophotometer based methods and sodium and potassium via atomic flame photometry (APHA, 2005) (Sherwood Flame Photometer 410). Sample pH was analysed using a Crison Basic 20+ pH meter, using buffer standardised buffer solutions for calibration. An ion-balance error calculation was undertaken on the 419 sample results to exclude from the final dataset individual samples that had an error of greater than $\pm 5 \%$. A total of 32 samples, ranging from 6 - $66 \%$ charge balance error, were excluded leaving 387 samples for data analysis. The survey provides the highest resolution 'snapshot' of groundwater hydrochemical data collated and evaluated for the Ngabu area to date.

Correlation coefficients were calculated using Minitab statistical software (Minitab Inc., 2017) to determine the relationships between hydrochemical parameters calculated using Pearson correlation coefficients. Statistical significance was determined using a two-tailed test at the 95\% confidence level.

\section{Results}

\subsection{Groundwater-quality survey}

\subsubsection{Summary data}

Descriptive statistics summarising the hydrochemical composition of the Ngabu groundwater dataset (Table 1) reveal an order of cation dominance of $\mathrm{Na}^{+}>\mathrm{Ca}^{2+}>\mathrm{Mg}^{2+}>\mathrm{K}^{+}>\mathrm{Fe}^{+}$and anion of $\mathrm{HCO}_{3}>\mathrm{Cl}^{-}>\mathrm{SO}_{4}{ }^{2-}>\mathrm{CO}_{3}{ }^{-}>\mathrm{NO}_{3}{ }^{-}$. The $\mathrm{pH}$ tends to be neutral to slightly alkaline. TDS values 
varied greatly, from $323 \mathrm{mg} / \mathrm{l}$ to over $10,000 \mathrm{mg} / \mathrm{l}$ with a median of $966 \mathrm{mg} / \mathrm{l}$. Wide variations in concentrations and relative compositions between samples signify a complexity of influential processes. The correlation matrix (Table 2) indicates salinity (TDS or EC) relationships with the various chemical parameters. TDS and EC demonstrated statistically significant positive correlations with $\mathrm{pH}$, bicarbonate, chloride, sulfate, nitrate, sodium, potassium, calcium and magnesium, but not carbonate or iron. $\mathrm{pH}$ showed statistically significant negative relationships with all major ion concentrations except sulfate. Near-neutral groundwater $\mathrm{pH}$ was associated with greater ion concentrations. Significant positive relationships were observed between the majority of ions analysed, excepting carbonate and iron, which only exhibited significant correlations with bicarbonate, nitrate, potassium, chloride and sulfate.

Table 1. Descriptive statistics for the 387 Ngabu groundwater samples

\begin{tabular}{lrrrrrc}
\hline \multicolumn{1}{c}{ Parameter } & Mean & Median & Minimum & Maximum & Standard deviation & Skewness \\
\hline $\mathrm{pH}$ & 7.6 & 7.5 & 7.1 & 8.9 & 0.4 & 1.2 \\
$\mathrm{EC}(\mu \mathrm{S} / \mathrm{cm})$ & 2523 & 1602 & 520 & 18510 & 2596 & 2.9 \\
$\mathrm{TDS}(\mathrm{mg} / \mathrm{l})$ & 1485 & 966 & 323 & 10050 & 1402 & 2.8 \\
$\mathrm{CO}_{3}{ }^{2-}(\mathrm{mg} / \mathrm{l})$ & 10 & 0 & 0 & 121 & 18 & 2.2 \\
$\mathrm{HCO}_{3}{ }^{-}(\mathrm{mg} / \mathrm{l})$ & 945 & 650 & 174 & 7950 & 824 & 2.9 \\
$\mathrm{Cl}^{-}(\mathrm{mg} / \mathrm{l})$ & 288 & 150 & 19 & 4306 & 528 & 4.6 \\
$\mathrm{SO}_{4}{ }^{2-}(\mathrm{mg} / \mathrm{l})$ & 60.1 & 33.7 & 1.5 & 783.0 & 77.6 & 4.9 \\
$\mathrm{NO}_{3}{ }^{-}(\mathrm{mg} / \mathrm{l})$ & 0.8 & 0.6 & 0.2 & 5.0 & 0.8 & 1.4 \\
$\mathrm{Na}^{+}(\mathrm{mg} / \mathrm{l})$ & 260 & 146 & 12 & 3145 & 396 & 4.0 \\
$\mathrm{~K}^{+}(\mathrm{mg} / \mathrm{l})$ & 4.2 & 3.1 & 0.2 & 33.0 & 4.6 & 2.8 \\
$\mathrm{Ca}^{2+}(\mathrm{mg} / \mathrm{l})$ & 175 & 120 & 13 & 1420 & 150 & 3.0 \\
$\mathrm{Mg}^{2+}(\mathrm{mg} / \mathrm{l})$ & 61.8 & 42.3 & 5.5 & 606.0 & 55.3 & 3.7 \\
$\mathrm{Fe}^{2+}(\mathrm{mg} / \mathrm{l})$ & 0.2 & 0.2 & 0.02 & 1.0 & 0.1 & 1.6 \\
$\mathrm{Mn}^{2+}(\mathrm{mg} / \mathrm{l})$ & $<0.001$ & $<0.001$ & $<0.001$ & $<0.001$ & 0 & $*$ \\
\hline
\end{tabular}

Table 2. Correlation matrix for chemical parameters of groundwater samples

\begin{tabular}{|c|c|c|c|c|c|c|c|c|c|c|c|c|c|}
\hline & $\mathrm{pH}$ & $\mathrm{EC}$ & TDS & $\mathrm{CO}_{3}{ }^{2-}$ & $\mathrm{HCO}_{3}^{-}$ & $\mathrm{Cl}^{-}$ & $\mathrm{SO}_{4}{ }^{2-}$ & $\mathrm{NO}_{3}{ }^{-}$ & $\mathrm{Na}^{+}$ & $\mathrm{K}^{+}$ & $\mathrm{Ca}^{2+}$ & $\mathrm{Mg}^{2+}$ & $\mathrm{Fe}^{2+}$ \\
\hline $\mathrm{pH}$ & - & & & & & & & & & & & & \\
\hline $\mathrm{EC}(\mu \mathrm{S} / \mathrm{cm})$ & $-0.146 *$ & - & & & & & & & & & & & \\
\hline TDS & $-0.107^{* *}$ & $0.988^{*}$ & - & & & & & & & & & & \\
\hline $\mathrm{CO}_{3}^{2-}$ & $0.762^{*}$ & -0.039 & 0.032 & - & & & & & & & & & \\
\hline $\mathrm{HCO}_{3}^{-}$ & $-0.220^{*}$ & $0.857^{*}$ & $0.890^{*}$ & $-0.169^{*}$ & - & & & & & & & & \\
\hline $\mathrm{Cl}^{-}$ & -0.092 & $0.901 *$ & $0.833^{*}$ & 0.003 & $0.564 *$ & - & & & & & & & \\
\hline $\mathrm{SO}_{4}{ }^{2-}$ & $0.110^{* *}$ & $0.559^{*}$ & $0.561^{*}$ & $0.384^{*}$ & $0.328^{*}$ & $0.559^{*}$ & - & & & & & & \\
\hline $\mathrm{NO}_{3}{ }^{-}$ & $-0.115^{* *}$ & $0.216^{*}$ & $0.236^{*}$ & $-0.131^{*}$ & $0.253^{*}$ & $0.156^{*}$ & -0.020 & - & & & & & \\
\hline $\mathrm{Na}^{+}$ & $-0.111^{* *}$ & $0.924^{*}$ & $0.867 *$ & -0.015 & $0.623^{*}$ & $0.990^{*}$ & $0.556^{*}$ & $0.185^{*}$ & - & & & & \\
\hline $\mathrm{K}^{+}$ & $-0.303^{*}$ & $0.357^{*}$ & $0.408^{*}$ & $-0.272^{*}$ & $0.501^{*}$ & $0.174^{*}$ & 0.051 & $0.329^{*}$ & $0.215^{*}$ & - & & & \\
\hline $\mathrm{Ca}^{2+}$ & $-0.169 *$ & $0.863^{*}$ & $0.897^{*}$ & -0.085 & $0.970^{*}$ & $0.586^{*}$ & $0.445^{*}$ & $0.190^{*}$ & $0.621^{*}$ & $0.449^{*}$ & - & & \\
\hline $\mathrm{Mg}^{2+}$ & $-0.112^{* *}$ & $0.739^{*}$ & $0.828^{*}$ & -0.019 & $0.940^{*}$ & $0.402^{*}$ & $0.362^{*}$ & $0.216^{*}$ & $0.445^{*}$ & $0.464^{*}$ & $0.939 *$ & - & \\
\hline $\mathrm{Fe}^{2+}$ & -0.054 & 0.093 & 0.055 & -0.060 & 0.049 & $0.110^{* *}$ & $0.176^{*}$ & -0.059 & $0.116^{* *}$ & -0.057 & 0.079 & -0.009 & - \\
\hline
\end{tabular}

NB: All parameters are in $\mathrm{mg} / \mathrm{l}$ except where otherwise stated

*significant at $99 \%$ confidence level

**significant at $95 \%$ confidence level 


\subsubsection{Distribution of hydrochemical water types}

Groundwater samples were separated into hydrogeochemical facies, according to the ions which made up more than $50 \%$ of the total ionic charge. The majority of samples (92\%) were classified as bicarbonate type, of which $29 \%$ were $\mathrm{Ca}-(\mathrm{Na})-\mathrm{HCO}_{3}$ type, $29 \%$ were $\mathrm{Na}-(\mathrm{Ca})-\mathrm{HCO}_{3}$, $16 \%$ were classified as $\mathrm{Na}-\mathrm{HCO}_{3}, 14 \%$ were $\mathrm{Ca}-(\mathrm{Mg})-\mathrm{HCO}_{3}, 12 \%$ were $\mathrm{Ca}-\mathrm{HCO}_{3}$ and $9 \%$ were mixed cation- $\mathrm{HCO}_{3}$ type. Approximately $8 \%$ of groundwater samples were of sodium chloride type, of which approximately $5 \%$ were $\mathrm{Na}-\mathrm{Cl}$ type, and approximately $3 \%$ were of $\mathrm{Na}-\left(\mathrm{HCO}_{3}\right)-\mathrm{Cl}$. The remaining groundwater samples $(0.8 \%)$ were of mixed cation-anion composition.

The spatial distribution of water types compared to contoured TDS (Fig. 2) generally shows the highest salinity areas are characterised by $\mathrm{Na}-\mathrm{Cl}$ groundwater mostly found in the area between the central plain and western bank of the Shire. Adjacent areas with slightly lower salinity tend to be of $\mathrm{Na}-\mathrm{HCO}_{3}, \mathrm{Na}-\left(\mathrm{HCO}_{3}\right)-\mathrm{Cl}$ and mixed ion water types attributed to the mixing of saline and fresher groundwater. Areas of medium salinity tend to be dominated by $\mathrm{Ca}-(\mathrm{Mg})-\mathrm{HCO}_{3}$, and mixed cation- $\mathrm{HCO}_{3}$. The lowest salinity values are associated with $\mathrm{Ca}-\mathrm{HCO}_{3}$, $\mathrm{Ca}-(\mathrm{Na})-\mathrm{HCO}_{3}$, and $\mathrm{Na}-(\mathrm{Ca})-\mathrm{HCO}_{3}$. These calcium-bicarbonate water types tend to predominate towards the west and southwest (Fig. 2). Plots of TDS versus $\mathrm{Na} /(\mathrm{Na}+\mathrm{Ca})$ and TDS versus $\mathrm{Cl} /\left(\mathrm{Cl}+\mathrm{HCO}_{3}\right)$ (Fig. 3; plot type after Monjerezi et al. (2012)) suggest the dominant processes controlling groundwater of low to medium TDS is rock weathering, whereas highly saline groundwater compositions may be attributed to a mixture of rock weathering and evaporation.

\subsubsection{Factors controlling salinity occurrence}

Controls upon the spatial distribution of salinity due to geology (aquifer) type, soil type and distance to the nearest river or fault is considered in Fig. 4 and are evaluated statistically via the Tukey pairwise comparison results (Supplementary Material, Tables SM1, SM2 and SM3). The majority of more saline water points occur within the central basin alluvial deposits. Elevated concentrations also occur in the northwest areas underlain by the Cretaceous Lupata sandstone (Fig. 4a). The most consistent low-salinity area occurred in the western basin areas where groundwater was drawn from the Karoo basalt basement rock. The Karoo basalt water points were significantly less saline than the alluvial aquifer and Lupata sandstone points (Table SM 1). 


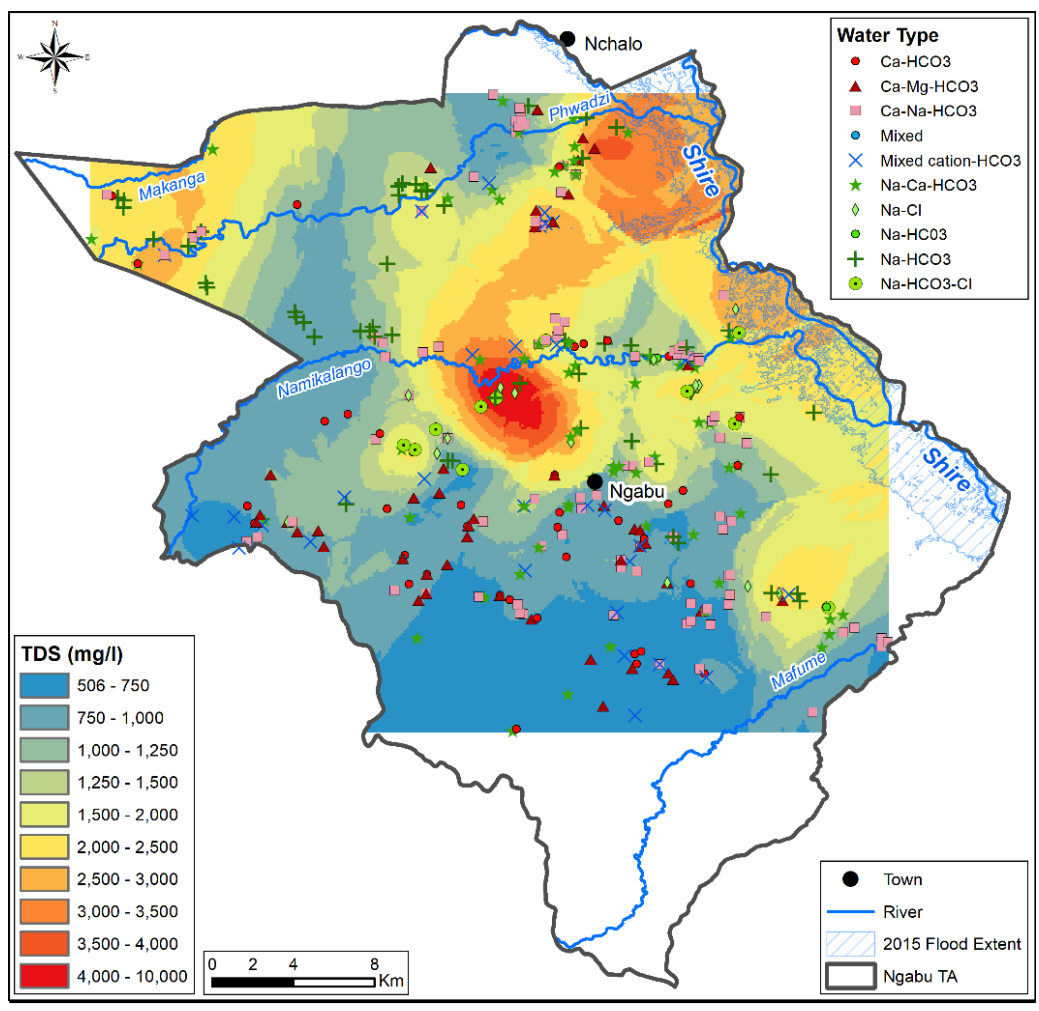

Fig. 2. Ngabu groundwater survey observed total dissolved solids (TDS) contoured and samples point groundwater type.
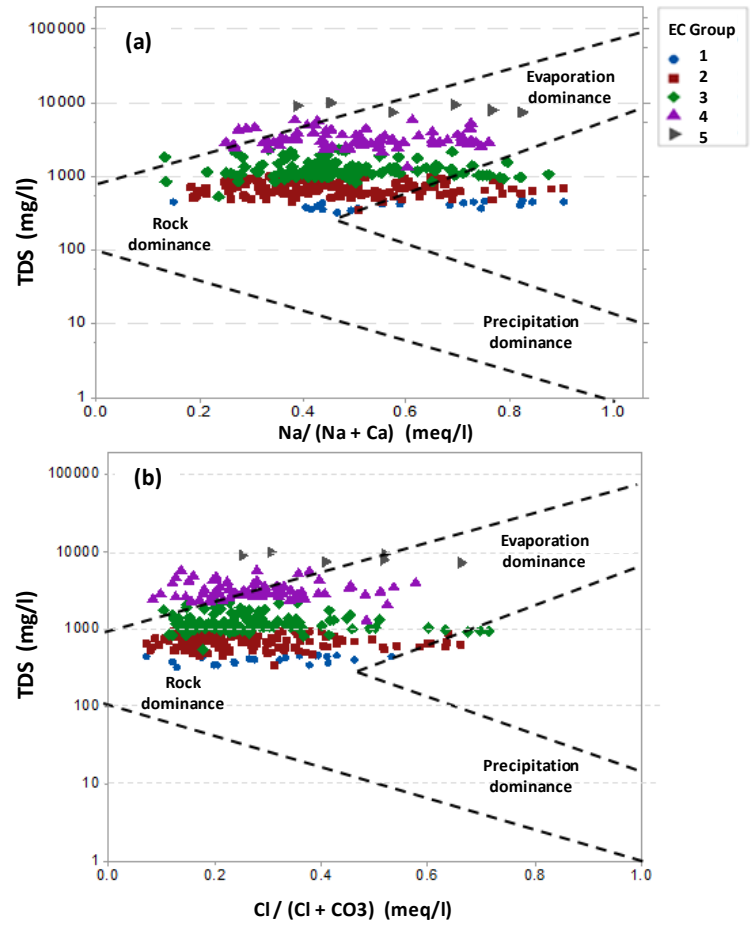

Fig. 3. Plots of (a) TDS vs. $\mathrm{Na} /(\mathrm{Na}+\mathrm{Ca})$ and (b) TDS vs. $\mathrm{Cl} /(\mathrm{Cl}+\mathrm{HCO})$, showing sources of dissolved ions with data categorised into EC groupings based on the MBS $(2005,2013)$ water quality guidelines (Group 1 is $520-700 \mu \mathrm{S} / \mathrm{cm}$; G2 is $701-1500 \mu \mathrm{S} / \mathrm{cm}$; G3 is $1501-3500 \mu \mathrm{S} / \mathrm{cm}$; G4 is $3501-10000 \mu \mathrm{S} / \mathrm{cm}$; G5 is $10001-18510 \mu \mathrm{S} / \mathrm{cm})$. 

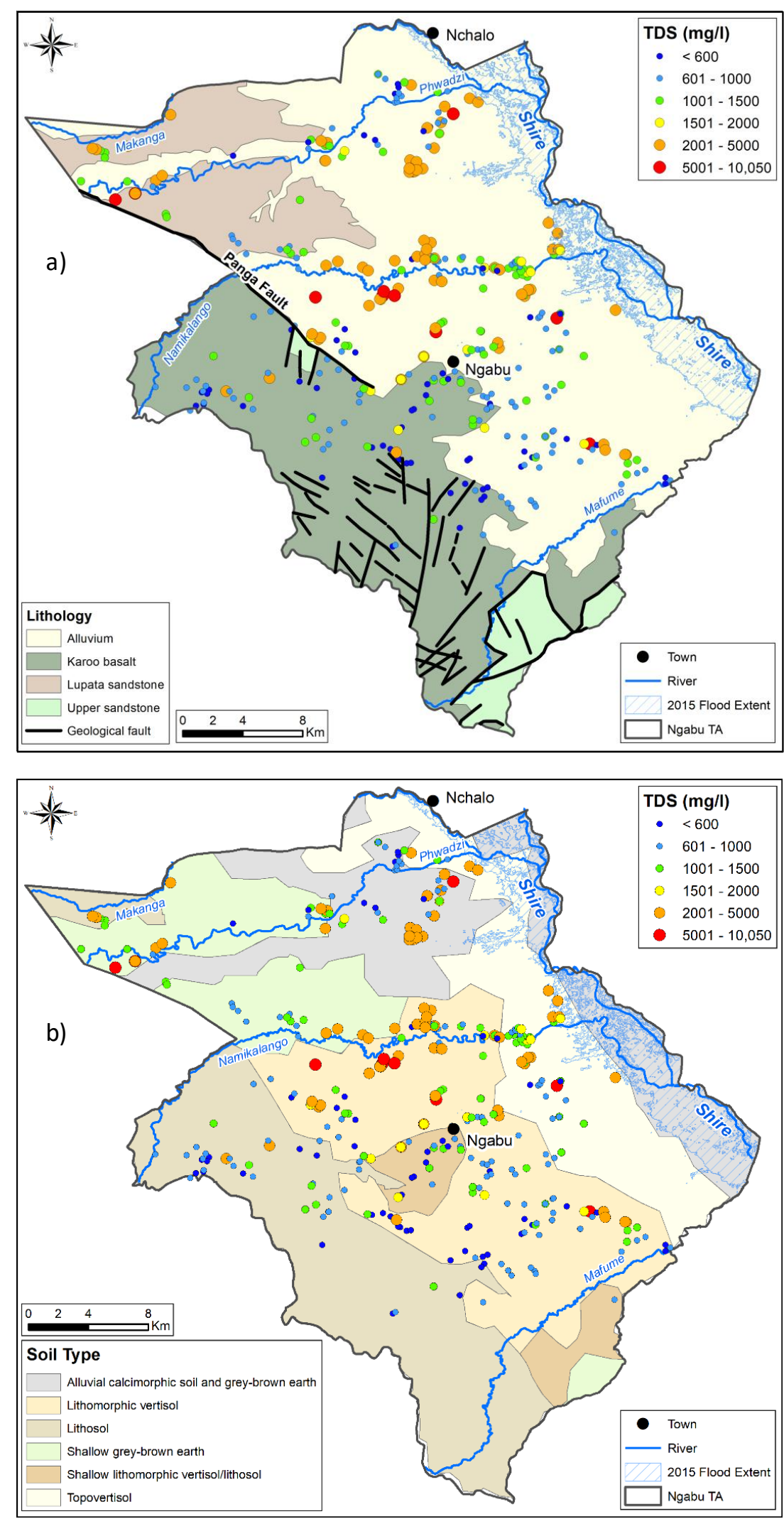

Fig. 4. Ngabu study area groundwater quality survey observed total dissolved solids (TDS) shown relative to (a) geology and (b) soil type. 
The majority of more saline groundwater occurs within areas overlain by lithomorphic vertisols soils of high expansive clay content prone to dry-season fracturing (Fig. 4b). Fairly elevated salinity occurs in areas characterised by topovertisols, alluvial calcimorphic soils and greybrown earths and shallow grey-brown earths. Low salinity was most consistently observed in lithosol areas to the west. EC was significantly higher in areas characterised by lithomorphic vertisols, topovertisols and shallow grey-brown earths in comparison to groundwaters sampled from areas characterised by lithosols (Table SM2).

Significant inverse relationships are confirmed for salinity with distance to the nearest river (Table SM3) and expected from periodic flood and evaporation cycles causing ion enrichment. Fig. 4 reveals near-river environments containing localised heterogeneous salinity hot-spot occurrence with other areas of blanketed elevated salinity. This suggests a need for increased sample-point density and consideration of water-abstraction depths to resolve controls upon salinity occurrence in transient near-river environments.

Whilst there is possible indication of increased salinity down hydraulic gradient of faults, for instance the Panga Fault (Fig. 4a), Pearson's correlation coefficients failed to confirm this (Table SM3); a slight positive correlation, opposite to that hypothesised, being found. It is recognised though preferential (e.g., fracture network) groundwater flow paths associated with fault zones are likely discrete with varying connectivity to water points sampled meaning relationships of increased salinity with fault proximity are challenging to resolve. Our wider sampling of springs and hand-pump boreholes near-fault areas in Southern Malawi to examine geothermal groundwater resource potential (Robinson, 2018) provides evidence of heterogeneous groundwater quality. Trends of increased TDS, sodium and chloride (and arsenic, lithium, and fluoride) are observed with increasing groundwater temperature sampled, ranging from 20 to $50{ }^{\circ} \mathrm{C}$. The data illustrate the control exerted by the proportion of warmer groundwater discharging from depth on local water quality present in the shallow aquifer system and used for supplies.

\subsubsection{Depth influence}

Assessment of (borehole) depth influence upon salinity observed was not viable from our hand-pumped survey data. Monjerezi et al. (2011a) though, in their wider Chikwawa survey, concluded variation of salinity with borehole depth did not display a significant pattern, with spatial variation being more apparent (depths typically spanning just 30-55 m). Within the wider CJF programme, efforts to resolve depth variation in salinity have focused upon the Mwanza Valley (northwest of the study area) where we have obtained EC depth profiles through sampling of borehole drilling return fluids during the installation of eight alluvialaquifer boreholes (Polmanteer and Kalin, 2014). Recognising such profiles are indicative (being subject to elevation and drilling fluid composition/mixing uncertainties), Fig. 5 displays two example profiles that reasonably bracket the dataset. 


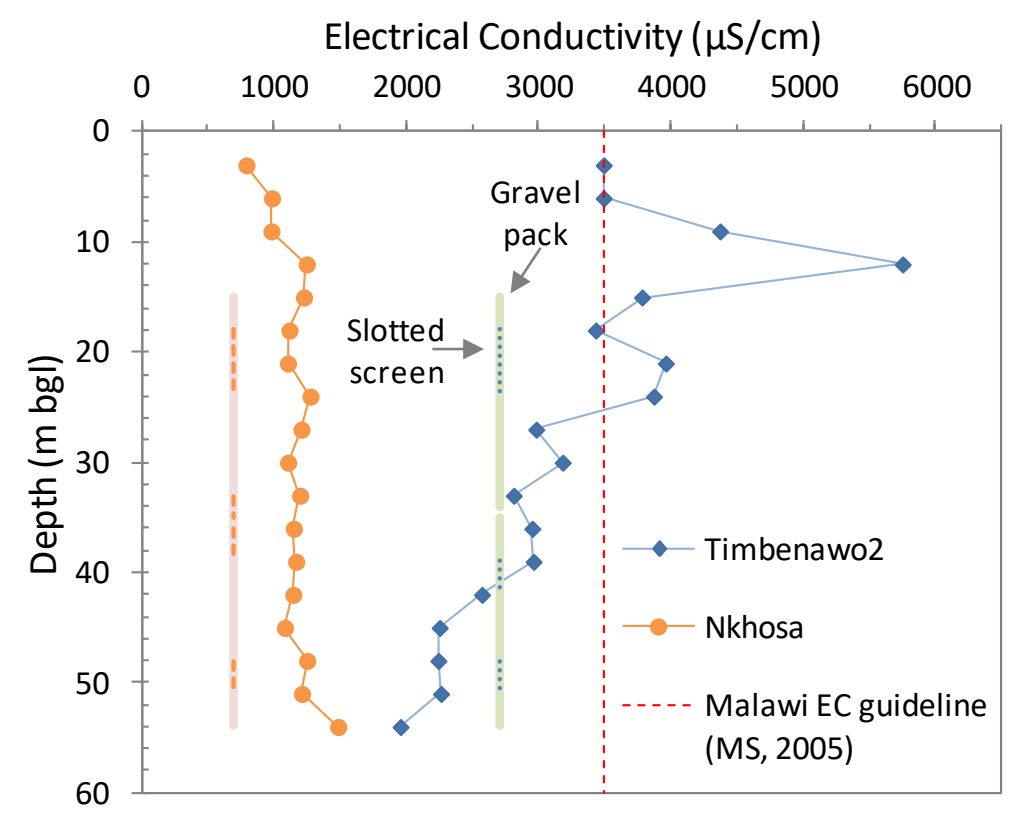

Fig. 5. EC profiles with depth obtained from the sampling of drilling fluid returns during the installation of two boreholes in the Mwanza Valley alluvial aquifer.

The Nkhosa site compares to three other profiles exhibiting fairly uniform EC 1-2000 $\mu \mathrm{S} / \mathrm{cm}$, although here, gradually increasing with depth. These contrast with other more variable profiles, represented by the highest EC Timbenawo case, that display shallow maxima around $3-6000 \mu \mathrm{S} / \mathrm{cm}$ (Fig. 5). The contrast is significant, especially considering their similar location just $1 \mathrm{~km}$ apart near the Mwanza River with water tables around $5 \mathrm{~m}$ depth. Although deeper drilling favoured Timbenawo water quality, it likely diminished Nkhosa quality. Sample quality pumped was $1566 \mathrm{mg} / \mathrm{l}$ TDS for Nkhosa and $1960 \mathrm{mg} / \mathrm{l}$ TDS for Timbenawo with concentrations of the latter likely sensitive to the borehole completion depth and gravel pack slotted screen positioning (shown). TDS just $25 \%$ higher than Nkhosa suggest groundwater is largely withdrawn from the mid to bottom of the borehole where salinity $(E C)$ is lower.

\subsection{Suitability for drinking-water supply}

Breaching of various water-quality criteria by surveyed water points is summarised in Table 3. The regulatory standard applied is the Malawi Standard MS733:2005 'Standard for water delivered from Boreholes and Protected Shallow Wells' (Malawi Standards, 2005) for which 'Maximum Permissible Levels' (MPLs) are set; distinction is not made as to whether individual MPLs have a health or aesthetic (e.g., taste) basis. MPLs are exceeded by around $20 \%$ of samples for TDS, EC and calcium and around $10 \%$ for sodium and chloride. Reference comparison with the upper limits of the Malawi Standard MS 214:2013 indicates greater percentages exceeding these more stringent criteria for 'Drinking Water Specification for treated drinking tap water' that 'does not apply to borehole water, bottled water and natural mineral water' (Malawi Standards, 2013). Notable percentages exceeding these are TDS and sodium at c. $90 \%$ of samples with significant percentages for other parameters. There is some 
justification for this comparison in that many water points will be directly used as drinking water.

Table 3. Summary of Ngabu groundwater quality 2016 survey data $(n=387$, except for TDS where $n=380$ ) tabulating water quality standard criteria and the percentage of samples exceeding these criteria in parentheses. Data are indicated relative to the relevant regulatory standard applied: Malawi Standard MS733:2005 'Standard for water delivered from Boreholes and Protected Shallow Wells' (Malawi Standards, 2005). Data are compared, for reference, to: the Malawi Standard MS 214:2013 for 'Drinking Water Specification for treated drinking tap water' (that 'does not apply to borehole water, bottled water and natural mineral water') (Malawi Standards, 2013); WHO (World Health Organisation) health-based guideline values (WHO, 2017), or taste or other aesthetic threshold estimates indicated in WHO supporting literature where health-based criteria are not stipulated for these parameters (WHO, 2017).

\begin{tabular}{|c|c|c|c|c|}
\hline & \multirow{2}{*}{$\begin{array}{l}\text { Regulation applied } \\
\text { Malawi Standard } \\
\text { MS733:2005 } \\
\text { Max. Permissible Level } \\
\text { Water from boreholes }\end{array}$} & \multicolumn{3}{|c|}{ Other Malawi and WHO criteria for comparison } \\
\hline & & $\begin{array}{l}\text { Malawi Standard } \\
\text { MS 214:2013 } \\
\text { Drinking Water } \\
\text { Specification - } \\
\text { upper limit }\end{array}$ & $\begin{array}{l}\text { WHO } \\
\text { Health-based } \\
\text { guideline value }\end{array}$ & $\begin{array}{l}\text { WHO } \\
\text { Aesthetic or } \\
\text { Taste threshold } \\
\text { estimate }\end{array}$ \\
\hline & (\% exceeding) & (\% exceeding) & (\% exceeding) & (\% exceeding) \\
\hline $\mathrm{EC}\left(\mu \mathrm{S} / \mathrm{cm}, 25^{\circ} \mathrm{C}\right)$ & $3500(22 \%)$ & $1500(54 \%)$ & $\mathrm{N} / \mathrm{A}$ & \\
\hline TDS (mg/l) & $2000(22 \%)$ & $500(92 \%)$ & $\mathrm{N} / \mathrm{A}$ & $1000 *(47 \%)$ \\
\hline $\mathrm{Cl}^{-}(\mathrm{mg} / \mathrm{l})$ & $750(8 \%)$ & $200(38 \%)$ & $\mathrm{N} / \mathrm{A}$ & $250(25 \%)$ \\
\hline $\mathrm{SO}_{4}{ }^{2-}(\mathrm{mg} / \mathrm{l})$ & $800(-)$ & $200(3 \%)$ & N/A & $250(2 \%)$ \\
\hline $\mathrm{NO}_{3}{ }^{-}(\mathrm{NO} 3, \mathrm{mg} / \mathrm{l})$ & $45(-)$ & $45(-)$ & $50(-)$ & \\
\hline $\mathrm{Na}^{+}(\mathrm{mg} / \mathrm{l})$ & $500(10 \%)$ & $50(89 \%)$ & $N / A$ & $200(82 \%)$ \\
\hline $\mathrm{Ca}^{2+}(\mathrm{mg} / \mathrm{l})$ & $250(20 \%)$ & $150(24 \%)$ & $\mathrm{N} / \mathrm{A}$ & 300 (17\%) \\
\hline $\mathrm{Mg}^{2+}(\mathrm{mg} / \mathrm{I})$ & $200(2 \%)$ & $70(74 \%)$ & N/A & $500(0.3 \%)$ \\
\hline $\mathrm{Fe}^{2+}(\mathrm{mg} / \mathrm{l})$ & $3(-)$ & $0.2(38 \%)$ & $\mathrm{N} / \mathrm{A}$ & $0.3(22 \%)$ \\
\hline
\end{tabular}

* unpalatable water 'brackish' threshold; N/A denotes 'not applicable' as standard not defined for parameter

None of the samples exceeded the WHO guideline values for drinking water health-based criteria (Table 3; WHO, 2017). Health-based guidelines are indicated by WHO not to be warranted for TDS, sodium, chloride etc. as levels found in drinking-water are not of health concern. WHO nevertheless recognises they may affect the acceptability of drinking-water (WHO, 2017) and note taste thresholds of c. $250 \mathrm{mg} / \mathrm{l}$ chloride and c. $200 \mathrm{mg} / \mathrm{l}$ for sodium. They regard drinking-water as having good palatability at a TDS of less than about $600 \mathrm{mg} / \mathrm{l}$ 
(just $17 \%$ of the Ngabu dataset), but that water becomes significantly and increasingly unpalatable at TDS levels over c. $1000 \mathrm{mg} / \mathrm{l}$. The taster survey of Bruvold and Ongerth (1969), cited in supporting WHO literature, classifies $900-1200 \mathrm{mg} / \mathrm{I}$ TDS as poor and $>1200 \mathrm{mg} / \mathrm{I}$ TDS as unacceptable. Comparison with the WHO aesthetic or taste threshold estimates (Table 3) reveals some $82 \%$ of water points could have a salty taste due to their sodium contents (recognising taste thresholds depend upon the associated anion and water temperature). The $1000 \mathrm{mg} / \mathrm{l}$ TDS brackish threshold was exceeded by nearly half of the water points. Ngabu data may hence be classified as $52.9 \%$ freshwater (< $1000 \mathrm{mg} / \mathrm{l}$ TDS), $46.8 \%$ brackish (1000-10000 $\mathrm{mg} / \mathrm{I} \mathrm{TDS}$ ) and $0.3 \%$ saline with one sample just over the 10,000 mg/I TDS threshold (Freeze and Cherry, 1979). The main water quality issue is hence the poor acceptability, or indeed unacceptability, of water for drinking on taste (palatability) grounds; a finding consistent with widespread community anecdotal evidence (verbal feedback primarily).

\subsection{Suitability for irrigation}

Although our main focus is upon domestic-drinking water supply, given the widespread and increasing use of groundwater for irrigation spanning a variety of scales, consideration of its suitability for this use is warranted (noting though the pending major initiative to use Shire River water canal irrigation in parts of the study area (Section 3.5.4)). Use ranges from smallholder private garden watering up to large farm enterprises and includes CBM initiatives such as borehole garden permaculture to help fund water-point maintenance (Rivett et al., 2018a). Metrics used to evaluate water suitability for irrigation, included salinity levels as EC or TDS, sodium percentage (\% Na), sodium adsorption ratio (SAR) and permeability index (PI) (Wanda et al., 2013) (Supplementary Material, Box SM1).

PI values varied from 27 to 112 (median 58) with 89\% of Class II 'good' (PI >25 - < 75) and 11\% Class I 'excellent' (PI >75). Class III 'poor' was not observed and hence all groundwater deemed suitable for irrigation based on this metric. The $\%$ Na median was $35 \%$ with a range of $8-84 \%$. Only $10 \%$ of water points exceeded the $60 \% \mathrm{Na}$ critical threshold rendering those water points unsuitable for irrigation with hence $90 \%$ suitable. SAR values suggested similar suitability (range 0.3-28.2 meq/l, median $2.7 \mathrm{meq} /$ ) with nearly $94 \%$ of water points having a low SAR (S1) and suitable for irrigation with $3.6 \%$ of medium (S2) possible concern. Uppermost classes, $2.3 \%$ as High (S3) and $0.3 \%$ as very high (S4), would pose significant irrigation issues as $\mathrm{Na}^{+}$ replaces $\mathrm{Ca}^{2+}$ and $\mathrm{Mg}^{2+}$ during cation exchange leading to dispersion of clay particles and breakdown in soil structure and reduced wettability.

EC salinity hazard classes (Fig. 6a) confirmed SAR generally increased with salinity. The least salinity hazard posed was medium with just $7 \%$ in group C2. $64 \%$ were high salinity hazard waters in the C3 range $750-2250 \mu \mathrm{S} / \mathrm{cm}$ with a further $29 \%$ classified as C4, very high salinity. Based on this metric, salinity may pose a widespread constraint upon irrigation use. Percentage occurrence of groundwater within the various threshold-based EC - SAR domains (Fig. 6a) reveals around $30 \%$ within the poor-quality domains, just over $50 \%$ in the medium quality and nearly $20 \%$ of good quality. Poor-quality domain groundwater may only be used for irrigation of salt tolerant or semi-tolerant crops in well drained soils. These data suggest there will be high risks to crop production and increased soil salinization, exacerbated by poor 
irrigation technique. The most appropriate areas for irrigation occur to the west and south west, towards the plain margins (Fig. 6b). Irrigation in central plain areas towards the Shire poses higher risk to crop production. The greatest sodium and salinity hazard for crop production occurs to the northwest of Ngabu town, close to the Namikalango River, where groundwater use for irrigation appears inappropriate.

a)

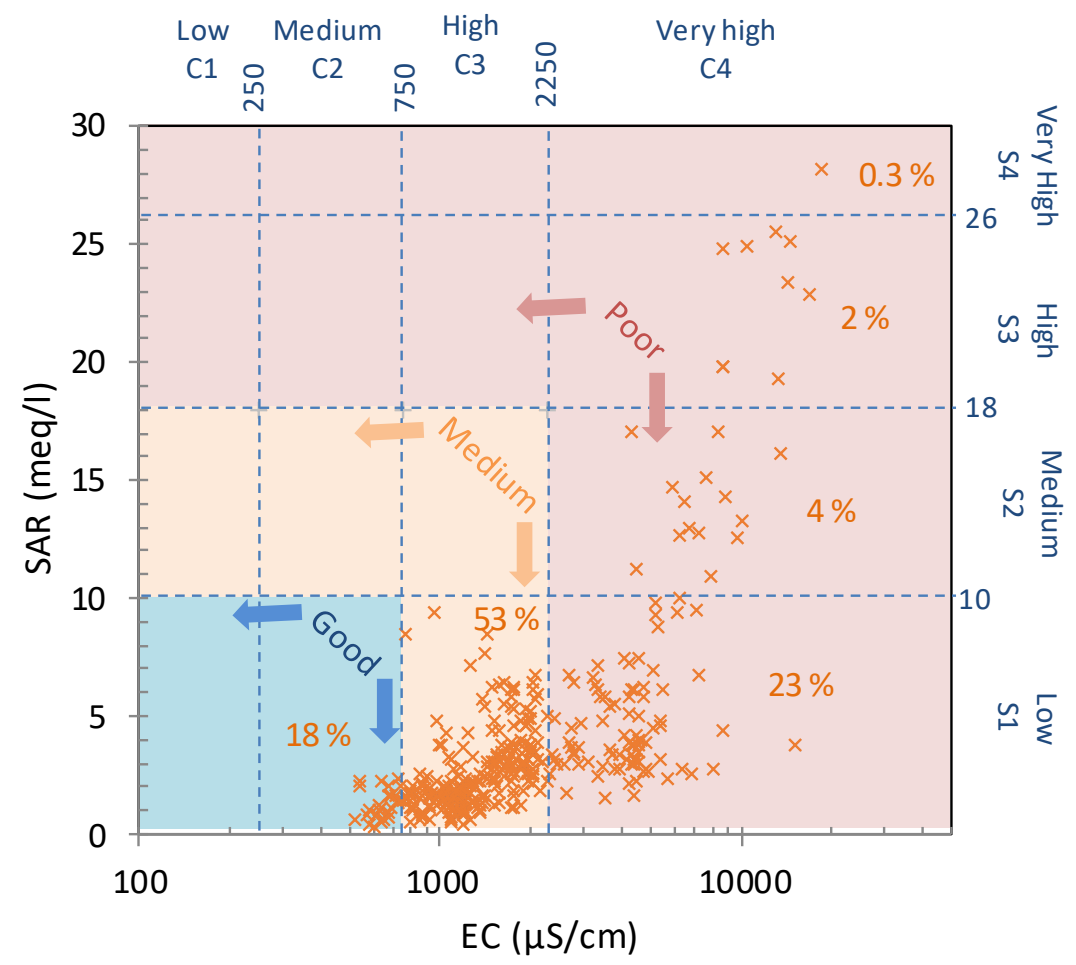

b)

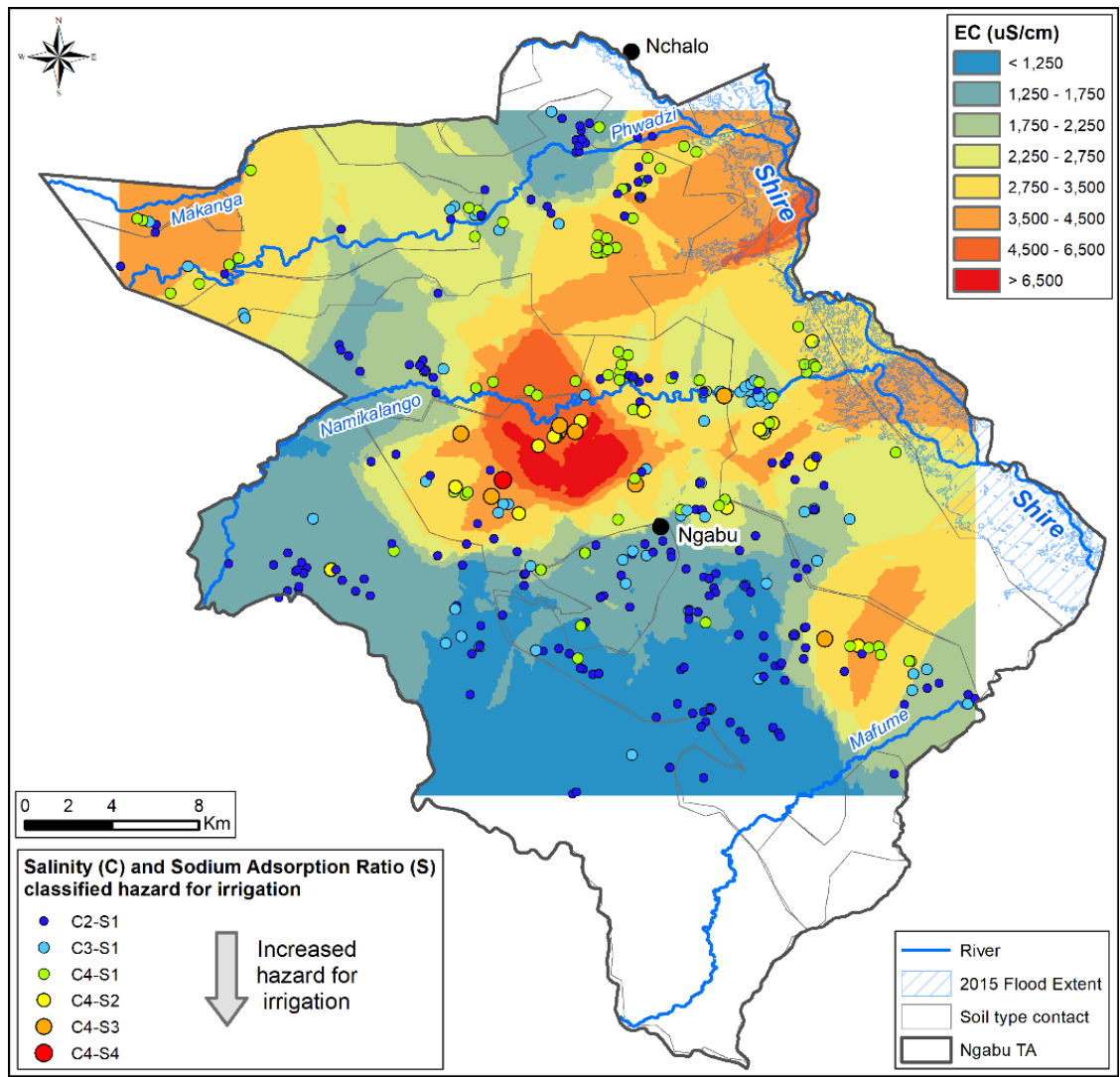


Fig. 6. (a) Plot of Ngabu groundwater survey sample salinity as electrical conductivity (EC) versus sodium adsorption ratio (SAR); (b) Ngabu study area contoured salinity (as EC) and sample point salinity and SAR classified hazard for irrigation use.

\subsection{Conceptual model of groundwater salinity occurrence}

The salinity problem faced by TA Ngabu is defined through a conceptual model of salinity occurrence relevant to drinking-water supply. The conceptualisation integrates our survey of groundwater salinity and review of the wider Chikwawa literature on groundwater-salinity controls. Our survey occurrence and consideration of controlling factors (Section 3.1) are endorsed and supplemented by that literature. Controls upon salinity occurrence are summarised in a sectional conceptual model (Fig. 7). Salinity generally increases down the hydraulic gradient, and with river proximity; recognising alluvial aquifers in Southern Malawi are epitomised by spatially heterogeneous salinity ascribed to low groundwater flows and dominant influence of local processes (Smith-Carington and Chilton, 1983). Key mechanisms are evaporation - direct and indirect (capillary action), chemical weathering and dissolution of (halite and gypsum) evaporitic salts, and upwelling in faulted areas (Bath, 1980; Smedley, 2004; Monjerezi et al., 2011a, 2012).

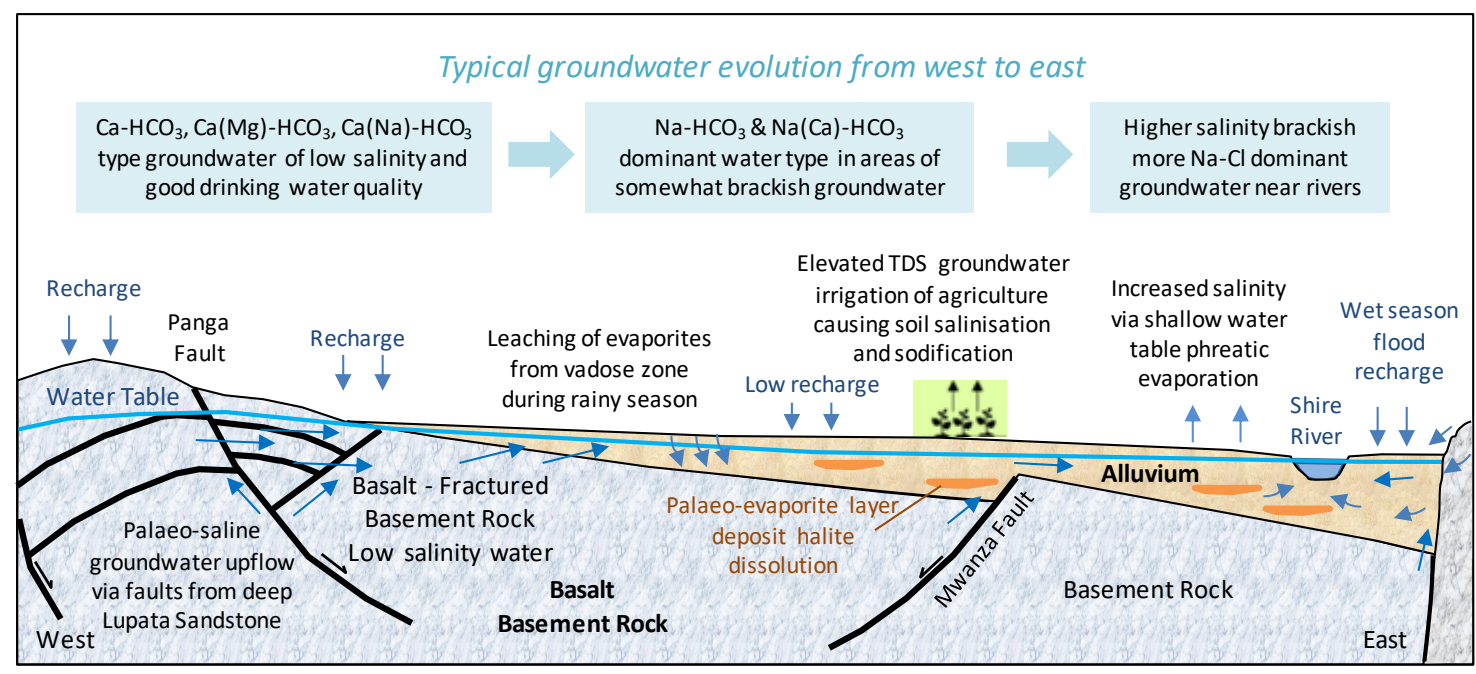

Fig. 7. Conceptual model of groundwater-salinity occurrence and controlling processes shown in cross section.

Elevated salinity with river proximity may arise from shallow (c. 1-3 $\mathrm{m}$ ) water table phreatic evaporation, low hydraulic gradients across the plain, and low flows in the frequent, low permeability, silt-clay laminations that may promote evapo-concentration of groundwater solutes (Bath, 1980; Bradford, 1973; Monjerezi and Ngongondo, 2012). Near-river groundwater can, however, show both elevated salinity suggestive of poor connectivity of groundwater on some river reaches, but also decreased salinity where ephemeral rivers recharge and dilute groundwater - for instance, observations on the Nyakambo River near Ngabu (Smith Carington and Chilton, 1983). 
Cyclic periods of wetting and drying following flood events also promote soil salinisation and sodification through capillary rise; evaporites re-dissolve in rainy season precipitation infiltrating back into shallow groundwater further enriching salinity. Evaporation enrichment is endorsed by significant linear correlations between sodium and chloride ions $(0.990 ; p<$ $0.001)$, chloride ions and other major ions and salinity parameters TDS (0.833) and EC (0.901) at the $99 \%$ confidence level (Table 2 ) alongside presence of sodic soils in the Shire floodplain (Monjerezi, 2012). Paleoclimate events may have influenced the sediment pile exerting longer period signatures. Evaporating pools of silty water arising from the wet-season deposition sedimentation of detrital deposits may favour interspersed evaporite occurrence within the silty-clay layers of the buried sediment pile (Addison, 2017; Bath, 1980). High resolution vertical profiling of salinity (via sampling or geophysical methods) is required to confirm the characteristics of layered evaporate occurrence within the alluvial aquifer sediment pile and still regarded a priority need. Mineralisation along fault zones and faulted area - fracture conduits may also release deep groundwater salinity to surface. Spatial heterogeneity in occurrence of saline groundwater arising in shallower units from such processes may be anticipated (Bath, 1980; Davis, 1969; Monjerezi and Ngongondo, 2012; Smith Carington and Chilton, 1983). Again, higher resolution monitoring is required to further discern local significances.

Quantitative plan-view conceptualisation of the salinity challenge to TA Ngabu drinking-water supply is visualised in Fig. 8. The conceptualisation is based upon data from the surveyed, $<50$ $m$ depth, shallow aquifer horizons sampled and may, or may not, represent deeper alluvialaquifer quality. Surveyed concentrations are shown categorised into: freshwater $(<1000 \mathrm{mg} / \mathrm{l}$ TDS); intermediate low-quality brackish water at > $1000 \mathrm{mg} / \mathrm{l}$ TDS (the WHO increasingly unpalatable transition point) up to $2000 \mathrm{mg} / \mathrm{l}$ (Malawi's MPL); and, very brackish water $>2000$ $\mathrm{mg} / \mathrm{I}$ TDS. The challenge salinity poses to supplies in the central plain to near-river areas is obvious. Whilst some freshwater supply points occur within these areas (i.e., blue water points contrasting with contour colouring in Fig. 8), freshwater supplies are more likely to be drawn from the alluvial deposits to the west and adjoining basalt Basement rocks. 


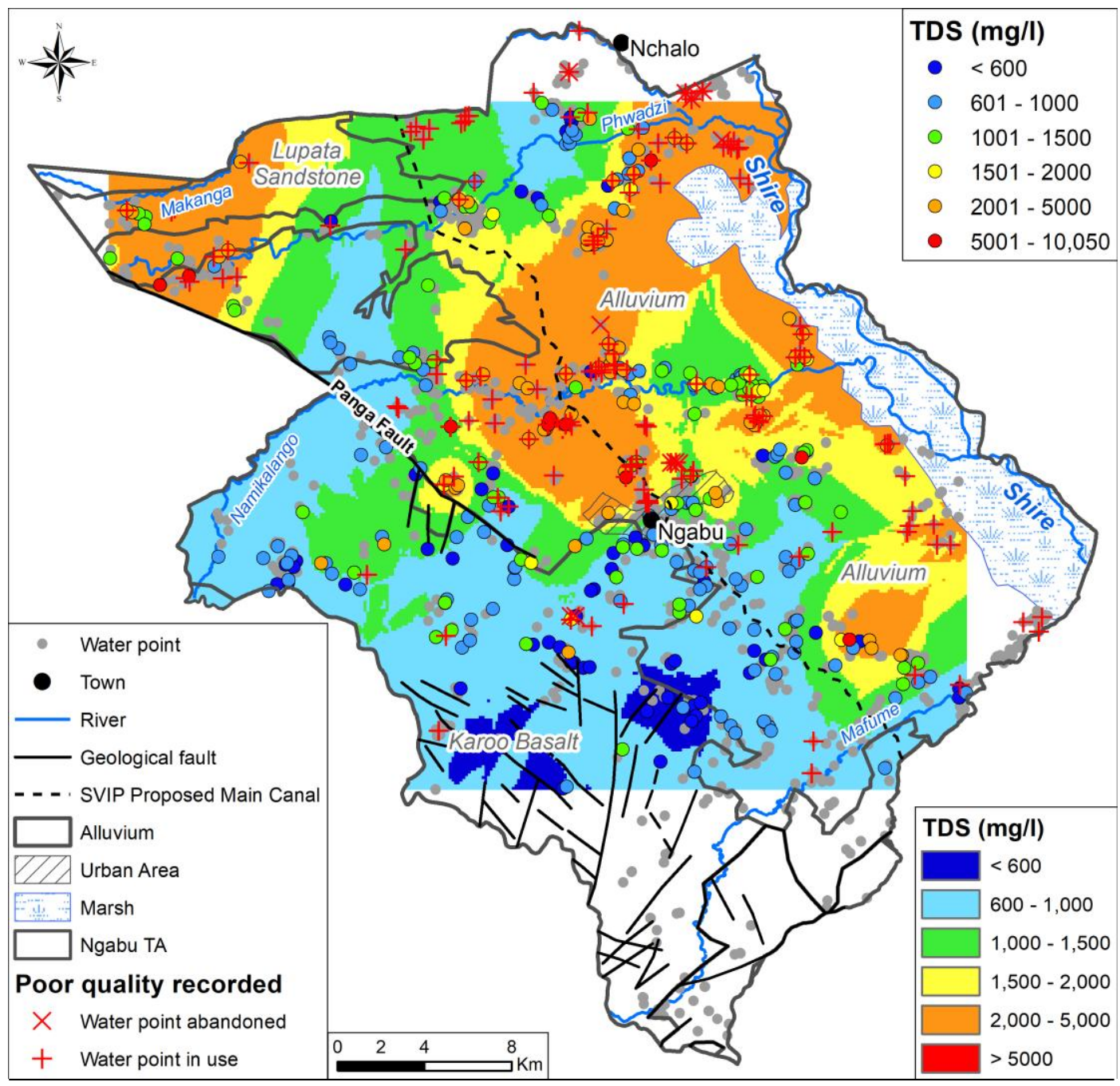

Fig. 8. Quantitative plan-view conceptualisation of the salinity challenge to TA Ngabu drinking-water supply: 2016 groundwater survey TDS data are plotted with blue colouration highlighting acceptable freshwater resource, green-yellow colouration poorer quality brackish water, and orange-red colouration the most saline, significantly brackish, groundwater. The 'poor water quality recorded' points are based upon 2016-17 survey community responses. The Shire Valley Irrigation Project (SVIP) proposed feeder canal route is shown for reference.

\subsection{Salinity-problem contextualisation}

Salinity-problem contextualisation is provided through supporting CJF water-point mapping data on groundwater resource development status, borehole functionality status, population pressures, and user-community salinity problem perception. A major irrigation initiative by the Government of Malawi, the Shire Valley Irrigation Project, is also introduced further below in that it poses significant contextual relevance and implications for groundwater salinity management in the study area.

\subsubsection{Groundwater resource use}


Groundwater utilisation for rural community supply has greatly increased in recent years as shown by the current distribution and temporal growth of water points across TA Ngabu and Chikwawa District (Fig. 9). Summary data are also provided in Table 4. For TA Ngabu, the 768 mapped boreholes comprise the vast majority (89\%) of water points; the remainder being 19 protected dug wells and 59 community taps (connected to tanks with groundwater supplies) that are concentrated around the Ngabu Town and Nchalo urban areas. The alluvial aquifer hosts the majority of water points. The recent proliferation of water points is obvious in Fig. 9 and attributed to WaSH programmes addressing Millennium Development Goal (2015 deadline) and on-going SDG 6 agenda. Some 44\% of mapped boreholes in TA Ngabu have been installed since 2011.

Table 4. Summary of water points and boreholes installed in the Chikwawa District and TA Ngabu.

\begin{tabular}{lcccc}
\hline & \multicolumn{2}{c}{ Chikwawa District } & \multicolumn{2}{c}{ TA Ngabu } \\
& Water Points & Boreholes & Water Points ${ }^{1}$ & Boreholes \\
\cline { 2 - 5 } & $1408(53 \%)$ & $1063(52 \%)$ & $493(57 \%)$ & $429(56 \%)$ \\
Installed pre-2011 & $836(32 \%)$ & $633(31 \%)$ & $211(24 \%)$ & $181(24 \%)$ \\
$2011-2015$ & $407(15 \%)$ & $339(17 \%)$ & $162(19 \%)$ & $158(21 \%)$ \\
2016 onwards $^{2}$ & 2651 & 2035 & 866 & 768 \\
Total & & & & \\
\hline
\end{tabular}

\footnotetext{
${ }^{1}$ A further 94 water points (93 of these are boreholes) of unknown age were mapped in Ngabu (Fig. 7b), but excluded from this analysis (it is quite probable many are old and abandoned boreholes, however the detail of these at present has not been pursued).

${ }^{2}$ The 2016 onwards data are provisional due to the on-going, around 85\% complete, 2016-18 survey work.
} 
a)

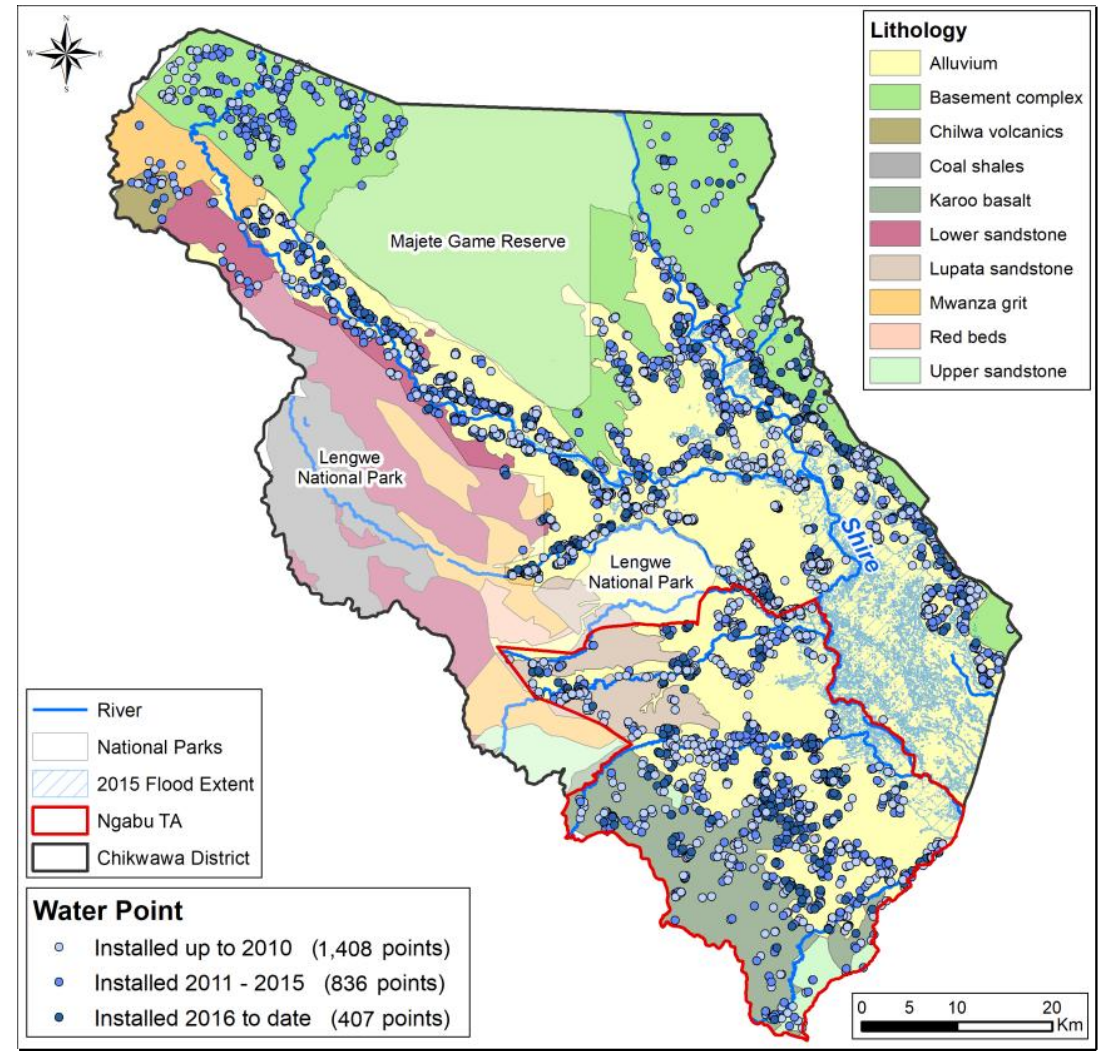

b)

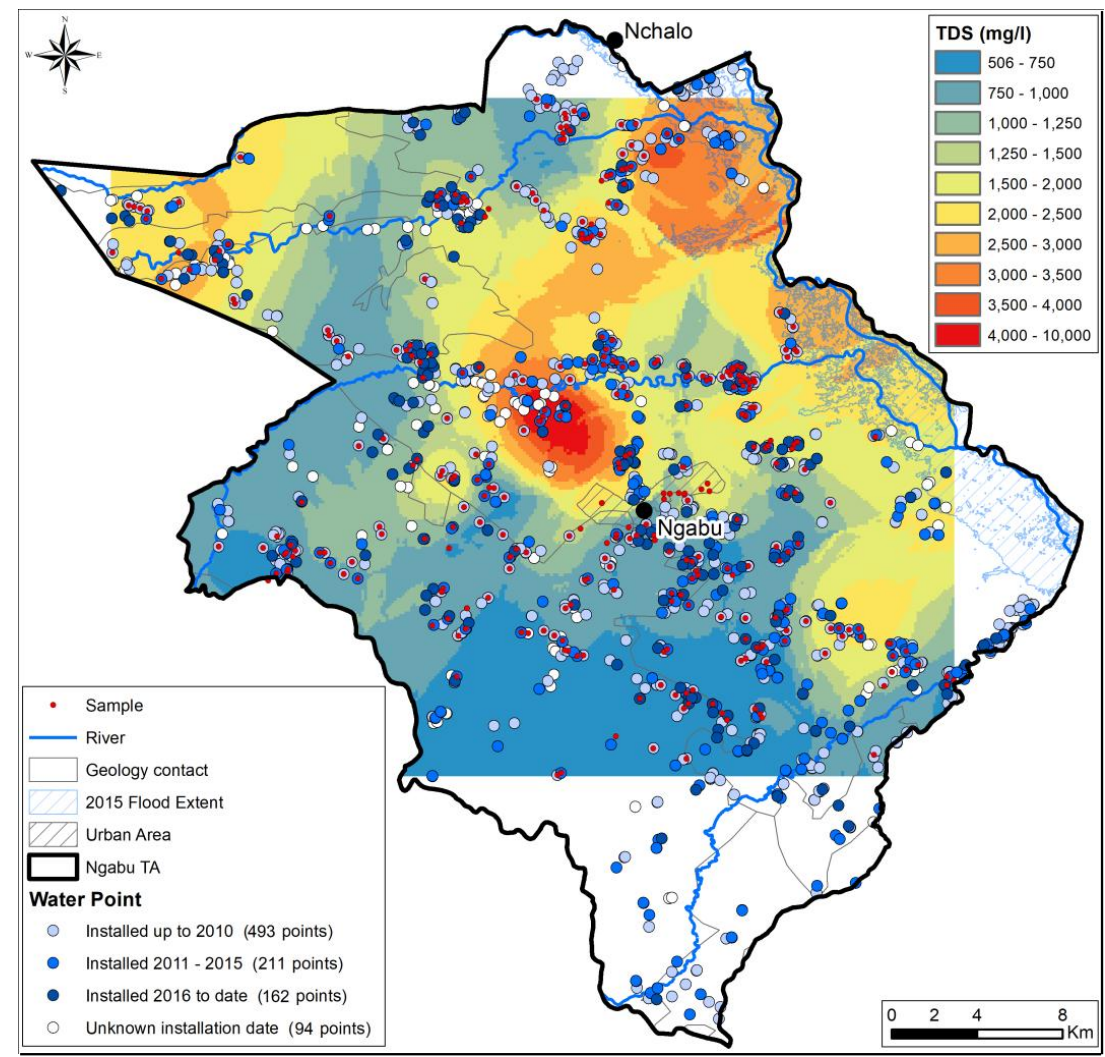

Fig. 9. All mapped water points for: (a) Chikwawa District including Ngabu TA relative to a geological background; and (b) Ngabu TA shown relative to the 2016 groundwater survey sampled water points and contoured TDS observed. 


\subsubsection{User community problem perception}

User community perception of salinity problems was revealed through a 2017-18 CJF survey that recorded $12 \%$ water points ( 80 boreholes) in TA Ngabu being judged by communities as having current 'poor water quality' problems. A further 11 boreholes were recorded as abandoned due to poor water quality (possibly a low estimate as some abandoned boreholes may not have been mapped). Poor water quality could relate to any of 'salty, bad taste or colour or other contamination' that were suggested, but not resolved, by the survey. Fig. 8 confirms most occurrences of 'poor quality recorded' water points were located in areas of elevated groundwater salinity. A further observation raising concern, is that $39 \%$ of the "poor water quality' boreholes were installed post 2012. Borehole water points classified as 'non functional' on the day of survey ( $n=190$ responses giving reasons) indicated the current problem was 'poor water quality, salty' in $15 \%(n=28)$ of cases. Other reasons typically related to more temporary problems: $48 \%$ of water points had broken or worn out parts, $10 \%$ had structural civil works problems, 9\% were newly constructed, $13 \%$ had low water flow or seasonal shortages, and $5 \%$ other reasons, e.g., vandalism. The authorship's experience is that elevated salinity is the primary reason for water-point abandonment, or the primary reason for long-term community concern (excepting chronic maintenance issues).

The lower percentage of boreholes (12\%) judged of poor water quality by communities, compared to those surveyed exceeding water-quality criteria (Table 3), probably relates to community toleration of less than ideal water quality for drinking-water - domestic supply, or signifies alternative water use being made. Communities commonly accept that some brackish water points may be suitable for washing, making bricks, irrigation, or watering livestock and that drinking water should be sourced from an alternative water point. A strategy though, that is inherently contingent upon local availability of water points of suitable drinking-water quality able to meet the increased demand.

\subsubsection{Population context}

Population distribution influences decision making on water-supply provision and salinity management. TA Ngabu's current (2015) population is low density and dispersed, largely across the habitable valley plain and margin foothills (Fig. 10a). More concentrated population occurs in Ngabu Town $(12,000)$ and around some river reaches. For the expected $3 \%$ annual population growth, the surveyed Ngabu TA 2008 population is projected to rise to 183,500 by 2016 and to 321,500 by 2035, more than doubling (122\%). Increased urbanisation is predicted, with Ngabu town accommodating 13\% of the TA Ngabu population by 2030 (currently 8\%) (National Statistical Office, 2008). Urban areas typically require much more water delivery per capita than rural. The design criteria used by the Central Region Water Board differs from 125 litres per person per day in Low Density Housing Areas to 36 litres in communal water points (CJF, 2018). 
a)

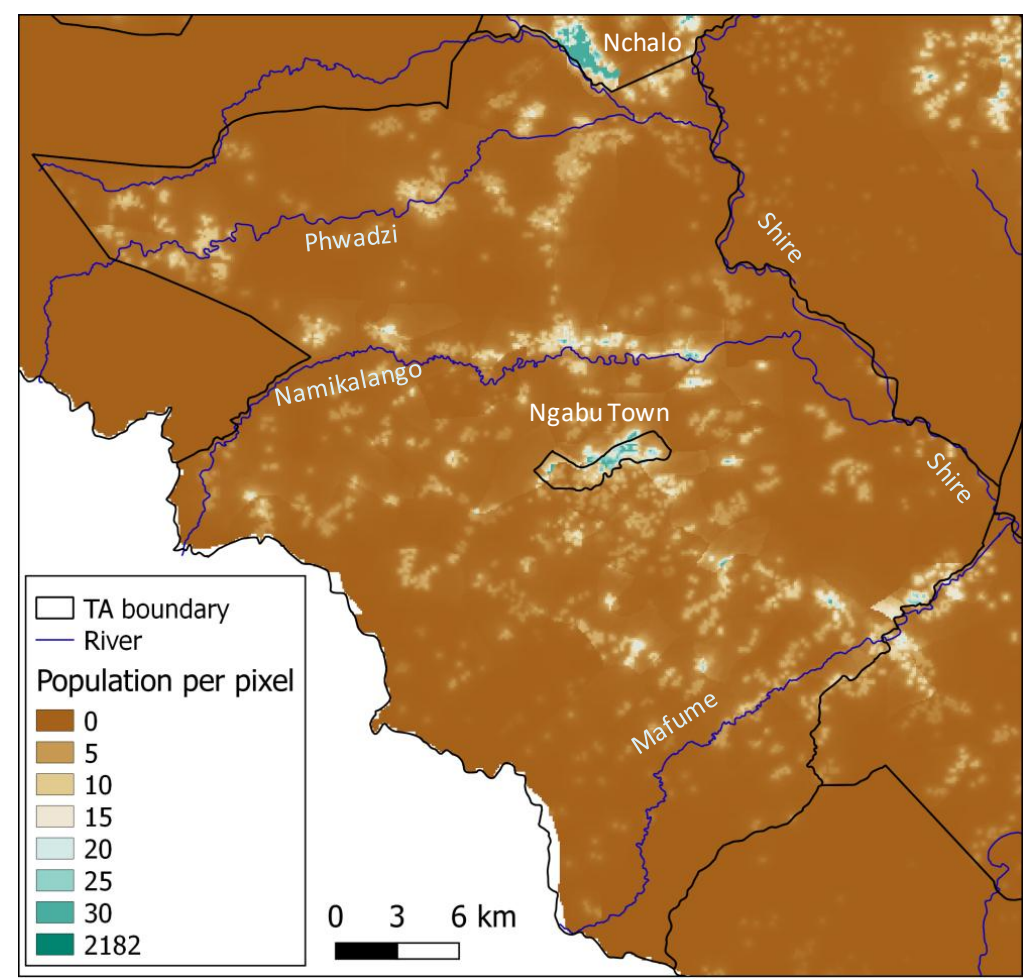

b)

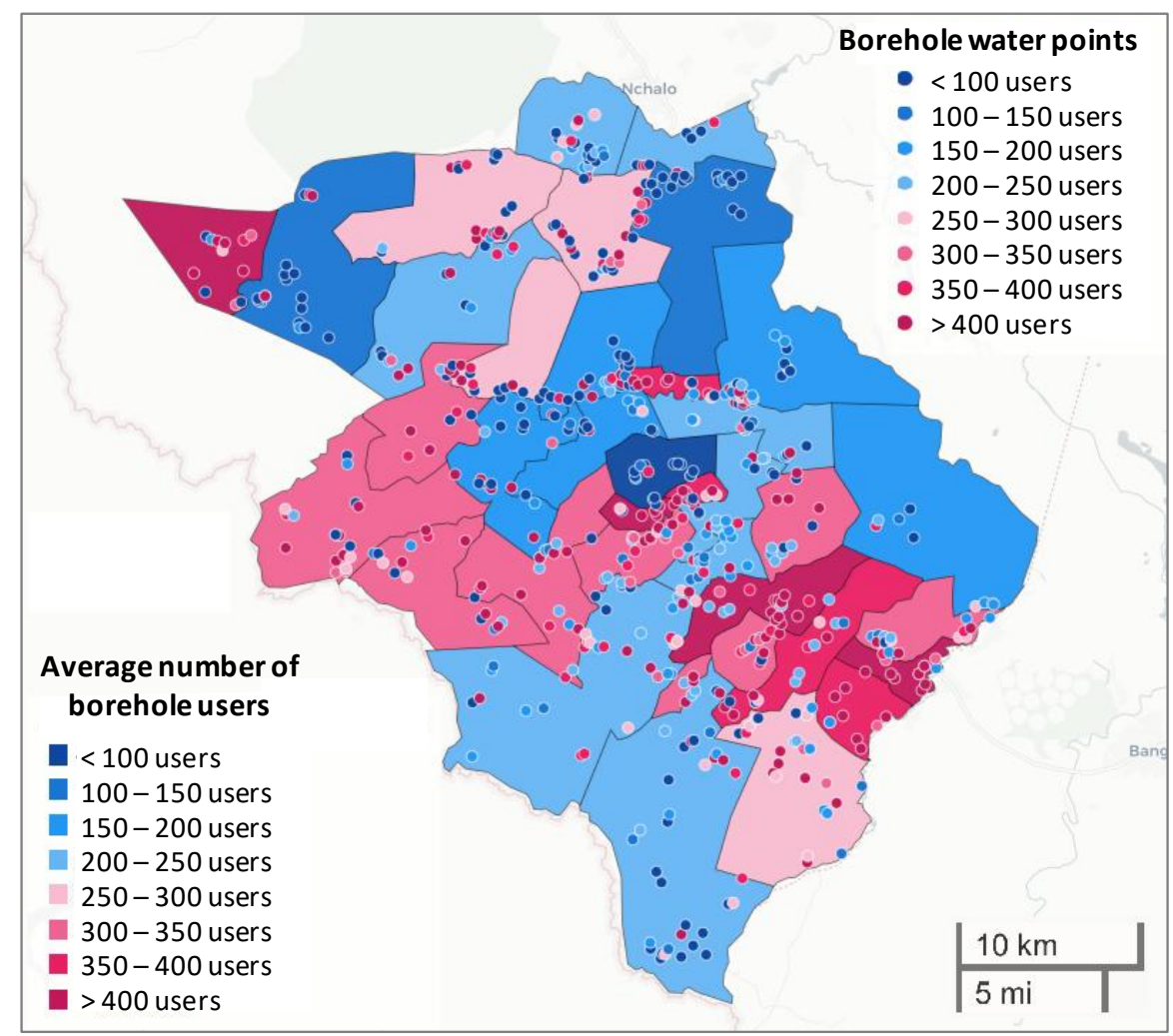

Fig. 10. (a) Population density map of TA Ngabu - data source: worldpop.org.uk (open access demographic data); (b) Chloropleth map for TA Ngabu showing the number of users per individual borehole (coloured circles) and the average number of users per borehole for all boreholes throughout a GVH (Group Village Headman) jurisdiction (coloured GVH area), based on our 2016 survey water point mapping responses (map created using mWater (www.mwater.co) dashboards, the open source Leaflet library and OpenStreetMap contributors). 
Current population pressures upon water points in TA Ngabu is indicated by the mapped number of users served by a borehole and the average user number for all boreholes across a GVH (Group Village Headman) area (Fig. 10b). These data may be compared to the National Water Resources Master Plan considers a design criteria of 250 people per borehole needing 36 litres per person per day $\left(9 \mathrm{~m}^{3} / \mathrm{d}\right.$, equivalent to $0.1 \mathrm{l} / \mathrm{s}$ ) (MoAIWD, 2017a). Blue colourations in Fig. 10b indicate that this goal is met, and red colouration not met (Fig. 10b). Local heterogeneity and uniformity in user numbers are both evident. Greater population pressures occur in the sparsely populated south east, in the less populated west containing few boreholes, and around the Namikalango River area. These areas of greater population pressure coincide with areas of both low and elevated salinity, as do the low pressure areas (compare Fig. 8 and Fig. 10b). Mean and median users per borehole across TA Ngabu are 268 and 210 users respectively ( $n=650$ boreholes) and very reasonably compare to 239 users per borehole independently estimated from TA Ngabu's 2016 total population and total number of boreholes (Table 4).

Factoring in borehole functionality is significant though as 33\% of the boreholes mapped by CJF were classified non-functional on the survey date. Only considering functional and partially functional boreholes $(n=438$ ) hence increases the mean and median to 357 and 300 users per borehole respectively, hence somewhat exceeding the above 250 users design criteria. Some mapped water points experienced significant demand with 1000 users reported at 4 sites and over 500 users at 14 sites.

\subsubsection{Shire Valley Irrigation Project}

The Government of Malawi's c. \$500 million (USD) World Bank and African Development Bank funded Shire Valley Irrigation Project (SVIP) is scheduled to commence construction in 2018. It is a major initiative to provide surface water for irrigation and agricultural development of the Shire Valley plain (MoAIWD, 2016b; MoAIWD, 2017b). The SVIP will divert c. $5 \%\left(20-50 \mathrm{~m}^{3} / \mathrm{s}\right.$ ) of the Shire River flow southwards from the Kapichira Dam (north of the study area) into 130 $\mathrm{km}$ of feeder canals and an associated drain network that allows gravity-fed irrigation of 45,000 hectares of land in Chikwawa District, including Ngabu TA, and the Nsanje District to the south (MoAIWD, 2016b). The proposed canal route, shown in Fig. 8, passes close to Ngabu Town, with proposed irrigation areas extending from the canal eastwards towards the Shire River. It is anticipated to bring farm modernisation and commercial farming opportunity to some 100,000 farming families, largely smallholders, and will provide poverty alleviation and economic opportunity for the population at large.

\subsection{Critique of current salinity response}

The combined authorship's wide and first-hand observational experience has permitted an informed critique of the current response capacity to groundwater salinity problems in 
Southern Malawi. WaSH sector operatives, their funders and individual donors have grown highly accustomed to expecting tangible images of water-supply success; an elated community drinking water from a long-awaited hand pumped borehole. It has become a well-practised, known process that incrementally brings water supplies to villages across a region. Despite growing concerns globally over water-point functionality (with some failures directly attributable to salinity) (Mannix et al., 2018), and hence effectiveness of hand pumps to securely deliver SDG6, there can be significant inertia to depart from this trusted model. In Malawi at least, few may have the hydrogeological experience of, or indeed vision for, alternative models of groundwater development. The international WaSH sector directly employs very few hydrogeologists, rather it consults that expertise on a perceived needs basis. This may lead to significant missed opportunity. The established handpump-borehole installation process in Malawi does not lend itself to addressing salinity problems, and in some ways can exacerbate the situation. Perceived key issues are summarised below.

\subsubsection{Water point location}

Requirements of proximal access to a water point cause borehole locations to be largely dictated by the locations of communities served, without explicit hydrogeological basis or intent to avoid areas of known salinity. Although hydrogeological considerations may be made, such as aiming to locally identify transmissive units alongside avoidance of known areas pollution sources (notably pit latrines (Back et al. (2018)), convenience of access still largely dictates water-point location, over favourable hydrogeological conditions (including salinity).

\subsubsection{Lack of experienced hydrogeologists}

In Malawi, organisations responsible for implementing borehole drilling initiatives rarely employ suitably qualified or experienced hydrogeologists. This leads to poor decision making during groundwater supply installation programmes. A suitably qualified hydrogeologist should be able to identify regional salinity risk, reduce chance of encountering salinity through good borehole siting techniques and supervise borehole construction to identify saline water occurrence before water point is commissioned for use. Monitoring salinity during borehole drilling in the alluvial sediments of Ngabu is made difficult by the necessary use of drilling muds, which can mask the influence of saline inflow horizons. The profiles shown in Fig. 5 do, however, demonstrate such monitoring may be useful, recognising the uncertainties involved. It is anticipated that the involvement of a suitably experienced hydrogeologist at all stages throughout groundwater supply programmes would pay dividends through significant improvements in yield, water quality, and long-term sustainability of installed water points (Adekile, 2014).

\subsubsection{Borehole drilling contracts}

Implementing organisations operating in Malawi have grown to expect extremely low borehole drilling costs. The Malawi average cost for a borehole equipped with a handpump is less than \$5000 (USD) compared to over \$10000 in Kenya, Tanzania and Mozambique (approximately updating Danert et al. (2009)). Many NGOs offer contracts at a fixed price per successful water point, with a no-pay clause for poor yield or poor water quality, and an 
expectation to drill, install, develop and test one water point in one day. This arrangement may lead to contractors cutting corners during the drilling, installation, development and testing phases of borehole construction, to ensure that a water point can be delivered as successful for the low contract price offered, within the tight timeframe. Relationships between borehole functionality and contracts are, however, nuanced and non-trivial to establish. Nevertheless, the CJF 2016-17 questionnaire survey of Ngabu water points reveals functionality rates of boreholes installed from 2013 onwards at 77\%, although much higher than those installed prior to then of $58 \%$, still remain well below that reasonably anticipated for modern, well engineered, installations.

\subsubsection{Lack of monitoring and research}

Whilst groundwater abstraction water-point infrastructure has been massively funded by international aid, there has been very little investment in groundwater-level or groundwaterquality monitoring networks to measure the impact of said abstraction. Since 2013, the regulatory body responsible for groundwater monitoring is the National Water Resources Authority (NWRA). Despite receiving some abstraction license and drilling permit income, the NWRA is acknowledged to be significantly under resourced to monitor and manage its groundwater; a significant task considering the rapidly growing tens of thousands of water points across Malawi (Miller et al., 2018). Currently the MoAIWD still operates only fledgling water-level or water-quality monitoring networks that are rarely sampled due to budget cuts (Rivett et al., 2018b). Whilst hydrochemical data should be obtained at water point installation, data archiving has been poor and the coordinates of water quality data frequently missing. There has been limited, research, use of hydrochemical-isotopic fingerprint methodologies that may help discriminate salinity origins (Chien and Lautz, 2018; Chowdhury et al., 2018; Eastoe, 2016) and vertical profiling of groundwater salinity variation (Section 3.1.4). Strategic capacity to proactively manage the complexity of groundwater salinity hence lacks.

\subsubsection{Enforcement of regulations}

In addition to the Water Resources Act 2013 (WRA, 2013) and Water Resources Regulations (in draft), the Malawi Government MoAIWD has published regulations on water quality and water point installation, however these are rarely enforced. The Government is in the process of establishing the NWRA created by the Water Resources Act (2013), however for now the institution's capacity to enforce these regulations and address these issues is limited severely by under-funding.

MoAIWD guidelines require new water points to be tested for microbiological contaminants, salinity and major-ions prior to commissioning. It appears such tests are not always completed and boreholes can be commissioned for use immediately post installation (Rivett et al., 2018b). Even where tests are conducted, results turn-around can occur weeks to months after the borehole is already in use. Where poor water quality is identified, results are not always appropriately acted upon. A water point may hence become inappropriately commissioned with decommissioning after unlikely. 
Legislative provision exists to help manage salinity. Malawi's Water Resources Act 2013 (article 77) states "any borehole which encounters salt water [...] shall be securely cased, plugged or sealed off [...]" and that it "shall apply to boreholes constructed or drilled before or after the commencement of this Act". However, such actions may not always be implemented due to technical capacity shortfalls, funding issues, poor enforcement and other, aforementioned, incentives to deliver a waterpoint.

\subsubsection{Co-ordination of organisations and activities}

Around 355 hand-pumped boreholes (45\% of total) have been installed in TA Ngabu since 2011 (Table 4). At an approximate price of (USD) $\$ 5000$ per water point, this equates to a $\$ 1.8$ million spend since 2011 on groundwater-supply infrastructure. Arguably, through better coordination and planning of organisations involved (NGO, private) and the government (MoAIWD), this capital investment could have been put to better use if combined into a single fund and utilised within larger scale regional planning, either within strategies that remain handpump-based but more coordinated, or alternative concerted strategies to provide water supply. Improved coordination between organisations and government within the rural water supply sector remains not only a Malawian, but also global, challenge (Garduño et al., 2010; Peiris, 2009; Smout, 1999).

\section{Discussion of future management options}

\subsection{Recommendations for improved hand-pumped water-supply practice}

Furnishing a better response to salinity problems, but continuing to still work at local waterpoint hand-pumped borehole scale, could include the following possible measures.

- Improved cross-sector practice, information exchange and collaborative research efforts focused in areas of resource salinity and set up of a working group(s) to coordinate efforts. This should include the reporting of successes and failures in an honest and transparent manner (often perceived to not be the case).

- Increased use of good practice following national guidance documents (Government of Malawi, 2016a,b) that are consistent with, or exceed international practices, e.g., those advocated by the Rural Water Supply Network (RWSN) (http://www.rural-watersupply.net/en/).

- Ensuring that a qualified hydrogeologist registered under Malawi's pending Water Resources Regulations (in draft) oversees the works (the regulations address the duties and powers of "qualified professionals and contractors", including hydrogeologists and water engineers, who will also need to comply with codes of practice and be included in a national register). All works should begin with a desk-study to understand the regional risks of salinity and prepare accordingly prior to commencement of site works. 
- Ensuring that the regulator is adequately resourced, has a good conceptual understanding of groundwater resources and their current use, and a skills basis for their management.

- Improved drilling contractual arrangements allowing fair re-imbursement for works undertaken, via an agreed bill of quantities for unsuccessful water points alongside development of sanctions that discourage inappropriate commissioning of water points not fit for supply.

- Employing a qualified hydrogeologist to supervise the works to ensure that fresh-water layers are targeted for screening, and steps are taken to ensure sub-standard water points are not commissioned for use.

- Where groundwater salinity occurrence is locally heterogeneous, promotion of data sharing between organisations to improve targeting of freshwater and research investigative effort to better understand salinity occurrence and its management.

- Where groundwater salinity appears consistently elevated, discouragement of repeat drilling attempts.

- Where groundwater is for agricultural use, to employ good irrigation practice that minimises evaporation and uses salt-tolerant or semi-tolerant crops in well drained soils.

- For the sector to proactively assist government regulation and monitoring and thereby underpin sustainable resource and salinity management.

Critical to the success of these, and alternative options below, is the development of Malawian national capacity. This not only includes technical skills development and the training and resourcing of hydrogeologists, water engineers, water resources managers, drillers and regulators, etc., but also robust mapping and management of the thousands of water points now present within a bespoke management information system. Development of national capacity in central to the Government's Master Plan (MoAIWD, 2017a) and CJF programme.

\subsection{Alternative options}

Handpumps are proven as a low cost, low maintenance and easily operated technology, but are limited by their yield and depth. Their 'point source' design does not allow for proliferation of a piped supply network. They are prone to low functionality rates. Instead of the continued proliferation of large numbers of individual water-point community supplies, especially in the areas with widespread salinity, there is a pressing need to consider alternative options that foster a more regional integrated water resources management (IWRM) practice. Recognising though, there are no easy answers. We provide outline discussion of: alternative groundwater supply schemes; surface-water supply schemes, including interface with the SVIP irrigation initiative; and, desalination. This does not preclude potential consideration of other options such as managed aquifer recharge (MAR), water re-use or rainwater harvesting. 


\subsubsection{Alternative groundwater supply schemes}

Boreholes in the Shire Valley alluvial aquifer can achieve very high yields exceeding $15 \mathrm{l} / \mathrm{s}$ $\left(1500 \mathrm{~m}^{3} / \mathrm{d}\right)$ where good borehole-installation practice is followed. They may provide significant resource opportunity (Mapona and Xie, 2014; Smith-Carington and Chilton, 1983). Yields are an order of magnitude greater than those achieved through hand pumps of approaching $0.5 \mathrm{l} / \mathrm{s}$ (Water Aid, 2013), or $0.25 \mathrm{l} / \mathrm{s}$ needed to commission a Malawian hand pump. Use of higher capacity boreholes and diesel generator or solar powered pumps (EED Advisory, 2018) markedly reduces the need to proliferate tens to hundreds of hand-pumped water points. Fewer boreholes need to be maintained and managed, and groundwater protection efforts become focused. Some local precedence is set by several large irrigation supplies and a few Southern Region Water Board boreholes supplying trading centres within Ngabu, Nchalo and Chikwawa Boma towns.

Larger volume supply schemes may be used to technically optimise abstraction from shallow or deep alluvial aquifers, an option recognised by the MoAIWD (JICA, 2018; CJF 2018). Cognisant though of their potential to cause increased impacts, improved hydrogeological resource management is required. Where a recently recharged freshwater resource is delineated overlying more saline groundwater, a moderate capacity well field of several dispersed boreholes may be appropriate with suitably positioned screen intervals and optimal abstraction rates to sustainable abstraction and minimise up-coning of deeper salinity. Special fractional or skimming wells could also be used (Van Weert et al., 2009). Horizontal abstraction drains or galleries may further reduce water-table lowering and salinity up-coning.

Development of deeper resources is cautioned by the generalisation that salinity tends to, but not always, increase with depth. Resource potential at depth is typically largely unknown due to the preferential exploitation of shallow units. This is the case for the Shire Valley alluvial system that thickens to around $150 \mathrm{~m}$ at its fault-bounded contact with the eastern escarpment (Smith-Carington and Chilton, 1983; Fig. 7). Up to $100 \mathrm{~m}$ thickness of extra resource thickness may be available compared to that accessed by hand-pumped boreholes. Yields may be further increased by borehole completion at larger diameter (>200 mm compared to $110 \mathrm{~mm}$ ). Critical though, is the water quality realised, with frequency of stratified salinity throughout the alluvial sediment pile a primary concern and borehole screening of low-salinity units a priority. Within alluvial systems generally, including Chikwawa (Smith-Carington and Chilton, 1983), more transmissive sand/gravel units tend to yield better quality groundwater and should be targeted via accurate logging and geophysical techniques. Although a research tool to the developing world, import of drive-point technologies that provide high-resolution in-situ vertical profiling of contamination (incl. salinity) (Pitkin et al., 1999) could help delineate freshwater horizons (providing a much more robust measurement of salinity depth profiles than possible from the sampling of drilling return fluids exemplified in Fig. 5 (still recommended to also undertake due to its ease and likely value)). Salinity encroachment may be reduced by several moderate capacity, rather than a single largecapacity, borehole.

Rural populations, although dispersed, may be connected to distant groundwater sources by judicious pipeline placements. Population urbanisation and gravitational draw to pipelines may 
increase economic viability. Preliminary location of fresh groundwater resources at (closest) distance from salinity impacted areas may be made by inspection of Fig. 8, cognisant that higher yielding alluvial units often occur closer to the valley margins as a result of fluvial deposition of large volumes of Quaternary sediments associated with rivers debouching from escarpments; especially within buried palaeo-channel - alluvial fan settings (Habgood, 1963; Smith-Carington and Chilton, 1983). Modern recharge is expected and enhanced by drainage from the hydraulically connected escarpment units. Good groundwater quality is also expected in the valley margin areas (Fig. 8), except possibly in faulted areas of deep salinity upflow. Gentle topographic fall from escarpments to the plain floor (Fig. 1a) may allow gravityaided pipeline with some pressurisation by initial pumping to elevated tank storage for local distribution probable. Although vast areas of good quality groundwater are not apparent in the alluvial system, some potential areas towards the west appear worthy of evaluation (Fig. 8). Feasibility studies would need to assess the potential for pipeline blockage, especially where calcium, magnesium and carbonate/bicarbonate concentrations are relatively high, to allow appropriate scheme design and management.

Development of larger groundwater schemes, although potentially hydrogeologically viable and capable of delivery of reticulated municipal supplies to greater population numbers, such schemes require long-term cost-benefit analysis considering financing, ownership, maintenance, management and sustainability concerns. Malawi's Water Resources Act (2013) advocates larger water supply schemes should be managed by a Water Users Association (WUA) under an enhanced and expanded CBM approach. However, it may be doubtful if that approach is viable for larger schemes. CBM in Malawi (and often elsewhere) has mostly been for the management of the water point infrastructure operation and maintenance, not management of the water resource itself at regional, or even local, scales. Larger schemes are likely to dictate the need for technical expertise and resource management expertise beyond that which communities can provide. Other options for ownership include a parastatal, government-owned, Water Board, a private water company, or a hybrid ownership. Such discussions are beyond the present scope, but vital. Certainly looking at the wider global literature on sustaining CBM at scale, better performing schemes are characterised by longterm external support including financial support, technical advice and managerial advice; and as internally, collective initiative, leadership and institutional transparency (Hutchings et al., 2015).

It is important to ensure any of the above schemes are developed within the context of sound regional water resource management. As a minimum, this would require 1) detailed understanding of sustainable water resource availability on a regional scale, 2) regional resource monitoring within different units, catchments or jurisdictions, 3) development of sustainable resource usage plans and 4) control of future abstractions via licensing and permitting. Identifying and managing groundwater salinity issues on a regional scale would allow alternative delivery options to be identified and utilised in a regionally sustainable manner. It would also facilitate the protection of precious fresh groundwater resources and their sustainable use. Establishment of a robust NWRA is seen critical to the regulation of larger schemes and regional management of resources and protection of the environment. 


\subsubsection{Surface-water options}

Initially ignoring the potential to interface with the SVIP canal-irrigation scheme, a pipeline to supply Ngabu town from the Shire River would require a $20-\mathrm{km}$ pipeline to lift water over a modest $50 \mathrm{~m}$ elevation change. To supply the town population of 16,000 at a low density housing supply rate of $125 \mathrm{l} / \mathrm{d}$, pipeline delivery of $0.023 \mathrm{~m}^{3} / \mathrm{s}$, representing c. $0.003 \%$ of Shire River flow would be required. Perennial rivers flowing west-to-east across the flood plain such as the Namikalango River may be closer to some populations, however, off-takes from these represent less secure options due to the very low, sometimes zero, dry-season flows (MoAIWD, 2016b) where meeting demand becomes most critical and would necessitate some form of supplementary support via dammed or subsurface water storage schemes. By way of comparison, the City of Blantyre (to the north) of 1 million population draws $90 \%$ of its 1.2 $\mathrm{m}^{3} / \mathrm{s}$ supply from the Shire River via a $48 \mathrm{~km}$ pipeline with an elevation rise to the city of some $800 \mathrm{~m}$. This is expensive water with $40 \%$ of operating costs relating to the cost of electricity to pump water (Maoulidi, 2012). Whilst, in the absence of gravity-fed pipeline distribution, some pumping operating costs remain in TA Ngabu, a key challenge remains the piped and pumped delivery and treatment of supply to the dispersed rural populations.

A gravity-fed canal system of distribution from the Shire River may offer significant advantage over pumped pipeline options (albeit recognising greater evaporation loss, etc.). The SVIP (Section 3.5.4) represents Southern Africa's largest irrigation project with canal feeder construction imminent and local consultation on water distribution arising from the feeder canal route on-going. The scheme is primarily for crop irrigation, but "will allow for livestock, small-scale water supply and other secondary benefits" (MoAIWD, 2016b); it is promoted as a "multiple-use (irrigation, domestic and livestock uses) irrigation and water programme" (MoAIWD, 2017b). At the very local scale this may entail canal-supplied water points are created for livestock, domestic and other social uses, and introduction of community water points (household tap water may not be feasible as houses are often temporary). At the larger scale, the SVIP may offer potential for pipeline transfer of drinking water - domestic supplies (with treatment) drawn from the feeder canal. A feasibility proposal for diversion and pipeline transfer to supply drinking water to Chikwawa town (north of our study area) is referred to by MoAIWD (2017b).

The proposed SVIP canal route across TA Ngabu passes through, and may irrigate, areas of elevated groundwater salinity (Fig. 8). With reference to drinking-water supply and groundwater salinity management, the SVIP presents significant opportunities, but also threats that require proactive consideration and management (as considered by Foster et al. (2018) elsewhere). A primary threat perceived is increased soil and groundwater salinity arising from poor irrigation practices that lead to excessive evaporation and salt accumulation; shallow water tables and elevated salinity areas being most vulnerable. Opportunities may exist though for irrigation to help flush salinity from the system. Also, the development of pipeline drinking-water supplies from the feeder canal that would render some of the aforementioned options redundant, notably longer, pumped, pipelines from the Shire River. The potential availability of surface-water supply may likewise offset the need to secure supplies of fresh groundwater. This is obviously valuable where groundwater salinity is pervasive in proximity to 
the canal route, for instance, around and north of Ngabu Town (Fig. 8), especially if deeper groundwater resources prove saline. More ambitious IWRM schemes may also be envisaged. Managed aquifer recharge at suitable hydrogeological localities may inject or infiltrate feeder canal higher flows in the wet season to aquifer storage that would be available for borehole extraction and supply in the dry season.

\subsubsection{Desalination water treatment}

Employment of desalination water treatment currently appears cost prohibitive within the developing world. Desalination technologies, however, are likely to prove more sustainable with time and become progressively more accessible to the developing world. Increased need for treatment of brackish groundwater for water supply in developed countries is driving down costs and advancing treatment methods bringing technologies closer to developing-world application. Emerging technologies include the solar-powered assisted, low-cost, green technologies such as the novel permeable graphene-based membranes recently outlined by Seo et al. (2018) and advanced novel membrane technologies potentially offering much more cost-effective desalination described by Tan et al. (2018). Once such desalination technologies become more cost-effective within the developing-world context, identifying the most appropriate scale at which brackish groundwater should be abstracted and treated may then represent a critical decision point. Timescales though for such technology development and deployment could still be decades away, rather than years.

\section{Conclusions}

Groundwater salinity occurrence in Ngabu may epitomise rural, semi-arid, valley alluvial aquifer scenarios elsewhere. Brackish groundwater commonly observed presented potable (palatability) drinking-water supply problems and could compromise irrigation use. Most derogation occurs in the central plain to near-river lowlands, with good, drinking-water, resource more common in the alluvial valley aquifer margins and escarpment Basement/bedrock. Survey results were consistent with the wider Chikwawa literature and permitted a conceptual model build of elevated salinity attributable to modern evaporation within near-river shallow groundwater, saline fossil water upwelling in faulted areas and dissolution of formation evaporite palaeo-deposits.

Salinity sources to individual boreholes, however, remain often unproven due to local data scarcity. In particular, characterization of the vertical heterogeneity of salinity and controls upon this occurrence represents a key need. It is technically viable and should be afforded to optimise both shallow and deep aquifer exploitation, and to safeguard against salinity migration induced from increased groundwater reliance. Contextual pressures due to population distributions and how these might be exacerbated by water-point functionality need to be understood, especially, as in the present case, persistent non-functionality or abandonment of boreholes is typically ascribed to elevated groundwater salinity. 
Authorship experience has allowed critical review of the current, in our view compromised, Malawian capacity to respond to groundwater salinity. Significant inertia is perceived within the WaSH sector to move beyond the trusted model of hand-pumped groundwater supply using low-capacity boreholes that incrementally bring supplies to villages. Where salinity is widespread, this is unlikely to be successful. Water-point locations being dictated by the location of the community served, a lack of experienced hydrogeologists, poor vision for larger capacity schemes, inappropriate borehole drilling contractual conditions, low drilling costs potentially compromising water-point integrity, and a lack of monitoring, research and regulatory enforcement alongside poor coordination of activities by the organisations involved, taken together, significantly hamper response capacity.

Is there a need to boldly go beyond the world of hand-pumped groundwater supply to respond to groundwater salinity in the developing world? Whilst commending a range of measures that may improve response capacity still continuing to work at the hand-pump borehole supply scale, where groundwater salinity is significant, we advocate a need to consider the versatility of other options. Indeed, salinity problems, where pervasive, may constitute the tipping point for the bold consideration of more ambitious schemes, cognisant that easy answers in the semi-arid developing world are unlikely. Alternatives will require careful feasibility study and multi-sector collaborative effort. For options progressed, the need for long-term external support should be considered to sustain schemes at scale and build an internal experience base.

The cornerstone of groundwater alternatives is the high potential borehole yields possible from alluvial aquifers, markedly under-exploited by hand pumps. A potential, that may be explored at depth (a largely unknown quality) or via pipeline transfer from known areas of good-quality groundwater, typically valley margin permeable alluvial deposits. Larger groundwater schemes will need to be designed, managed and regulated by qualified hydrogeologists to provide adequate safeguards. Major surface-water supply schemes are typically constrained by pipeline transfer distances involved and dispersed communities present; hence targeting of (growing) population centres preferred. For major irrigation schemes (as proposed for the Lower Shire Valley), it is imperative these do not exacerbate groundwater salinity problems, but realise opportunities offered, including drinking water supplies from the feeder canal or consider managed aquifer recharge type initiatives. Desalination technologies are advancing and likely to become, in time, increasingly sustainable and affordable to the developing world. Future scales of brackish groundwater desalination then employed will require careful consideration for their optimal use in the rural developing world.

The presented Malawian case of groundwater salinity occurrence, response capacity critique and outline consideration of response options is anticipated relevant to salinity management in similar developing-world aquifer systems largely developed by hand-pump supplies. Consideration should likewise be given to the need to boldly go beyond the world of handpumped groundwater supply to safeguard supplies from salinity concerns. 


\section{Acknowledgements}

We gratefully acknowledge the funding of this research by the Scottish Government under the Scottish Government Climate Justice Fund Water Futures Programme research grant HN-CJF03 awarded to the University of Strathclyde (R.M. Kalin).

\section{Appendix A. Supplementary material}

Supplementary material associated with this article can be found in the online version at http://dx.doi.org/〉>>

\section{References}

Abu-alnaeem, M.F., Yusoff, I., Ng, T.F., Alias, Y., Raksmey, M., 2018. Assessment of groundwater salinity and quality in Gaza coastal aquifer, Gaza Strip, Palestine: An integrated statistical, geostatistical and hydrogeochemical approaches study. Sci. Tot. Environ., 615, 972989. https://doi.org/10.1016/j.scitotenv.2017.09.320

Addison, M., 2017. A spatial distribution analysis of salinity in an inland, saline-contaminated aquifer, Ngabu, Southern Malawi. MSc Hydrogeology thesis (unpublished), Department of Civil and Environmental Engineering, University of Strathclyde.

Adekile, D., 2014. Supervising water well drilling. A guide for supervisors, RWSN/UNICEF, Rural Water Supply Network, St Gallen, Switzerland. http://www.rural-watersupply.net/en/resources/details/392

Ali, R., Salama, R., Pollock, D., Bates, L., 2002. Geochemical Interactions between Groundwater and Soil, Groundwater Recycling and Evaporation in the ORIA. CSIRO Land and Water, Perth Technical Report 21/02. http://www.clw.csiro.au/publications/technical2002/tr21-02.pdf

APHA (American Public Health Association), 2005. Standard methods for the examination of water and wastewater. American Public Health Association (APHA): Washington, DC, USA.

Argamasilla, M., Barberá, J.A., Andreo, B., 2017. Factors controlling groundwater salinization and hydrogeochemical processes in coastal aquifers from southern Spain. Sci. Tot. Environ., 580, 50-68. https://doi.org/10.1016/i.scitotenv.2016.11.173

Back, J.O., Rivett, M.O., Hinz, L.B., Mackay, N., Wanangwa, G.J., Phiri, O.L., Songolo, C.E., Thomas, M.A.S., Kumwenda, S., Nhlema, M., Miller, A.V.M., Kalin, R.M., 2018. Risk assessment to groundwater of pit latrine rural sanitation policy in developing country settings. Sci. Tot. Environ., 613-614C, 592-610. https://doi.org/10.1016/j.scitotenv.2017.09.071

Bath, A.H., 1980. Hydrochemistry in groundwater development: report on an advisory visit to Malawi. British Geological Survey Report WD/OS/80/20. http://nora.nerc.ac.uk/id/eprint/505535 
Bennet, J.D., 1972. Magnetic investigations of the extensions of the Matumba, Mwanza and Namalambo faults beneath the alluvium and colluvium of the Lower Shire Valley. T580. Geological Survey of Malawi.

Bonsor, H., MacDonald, A., Casey, Carter, R., Wilson, P., 2018. The need for a standard approach to assessing the functionality of rural community water supplies. Hydrogeol. J., 26, 367-370. https://doi.org/10.1007/s10040-017-1711-0

Bonsor, H.C., Oates, N., Chilton, P.J., Carter, R.C., Casey, V, MacDonald, A.M., Calow R., Alowo, R., Wilson, P., Tumutungire, M., Bennie, M., 2015). A hidden crisis: strengthening the evidence base on the sustainability of rural groundwater supplies-results from a pilot study in Uganda. OR/15/019, British Geological Survey, Nottingham, UK. http://nora.nerc.ac.uk/id/eprint/511071/

Boukhari, K., Fakir, Y., Stigter, T.Y., Hajhouji, Y.,. Boulet, G., 2018. Origin of recharge and salinity and their role on management issues of a large alluvial aquifer system in the semi-arid Haouz plain, Morocco. Environ. Earth Sci. (2015) 73: 6195. https://doi.org/10.1007/s12665$\underline{014-3844-y}$

Bradford, R.B., 1973. Groundwater reconnaissance study: lower Shire Valley. Report RB/5. File T601. Geol. Surv., Malawi. https://www.bgs.ac.uk/sadc/fulldetails.cfm?id=MW1202

Bruvold, W.H., Ongerth, H.,J., 1969. Taste quality of mineralized water. J. Am. Water Works Assoc., 1969, 61-170. http://www.jstor.org/stable/41266078

Budimir, L., 2017. Chemical evaluation of groundwater quality in the Traditional Authority of Ngabu, Malawi: suitability for drinking and irrigation use. MSc Hydrogeology thesis (unpublished), Department of Civil and Environmental Engineering, University of Strathclyde.

Burney, J.A., Naylor, R.L. and Postel, S.L., 2013. The case for distributed irrigation as a development priority in sub-Saharan Africa. Proceedings of the National Academy of Sciences, 110(31), 12513-12517. https://doi.org/10.1073/pnas.1203597110

Carter, R.C., 2015. Long live the humble handpump. Presentation ID 168, Session S1.1a, 42nd Congress of the International Association of Hydrogeologists, Rome, September 2015.

https://upgro.files.wordpress.com/2015/09/carter-id-n168-session-s1-1a.pdf Carter, R.C., Ross, I., 2016. Beyond 'functionality' of handpump-supplied rural water services in developing countries. Waterlines, 35(1), 94-110. https://doi.org/10.3362/1756-3488.2016.008

Castaing, C., 1991. Post-Pan-African tectonic evolution of South Malawi in relation to the Karoo and recent East African rift systems. Tectonophysics, 191, 55-73. http://dx.doi.org/10.1016/0040-1951(91)90232-H

Chen, H., Liu, Z., Huo, Z., Qu, Z., Xia, Y., Fernald, A., 2016. Impacts of agricultural water saving practice on regional groundwater and water consumption in an arid region with shallow groundwater. Environ. Earth Sci., 75(16), 1204. https://doi.org/10.1007/s12665-016-6006-6

Chien, N.P., Lautz, L.K., 2018. Discriminant analysis as a decision-making tool for geochemically fingerprinting sources of groundwater salinity. Sci. Tot. Environ., 618, 379-387. https://doi.org/10.1016/j.scitotenv.2017.11.019

Chowdhury, A.H., Scanlon, B.R., Reedy, R.C., Young, S., 2018. Fingerprinting groundwater salinity sources in the Gulf Coast Aquifer System, USA. Hydrogeol. J., 26, 197-213. https://doi.org/10.1007/s10040-017-1619-8 
CJF (Climate Justice Fund: Water Futures Programme), 2018. Preliminary survey on the Groundwater Development Plan. Submitted to the Ministry of Agriculture, Irrigation and Water Development, Government of Malawi.

Coulibaly, J.Y., Mbow, C., Sileshi, G.W., Beedy, T., Kundhlande, G. and Musau, J., 2015. Mapping vulnerability to climate change in malawi: spatial and social differentiation in the Shire River Basin. American Journal of Climate Change, 4, 282-294. https://doi.org/10.4236/ajcc.2015.43023

Danert, K., Carter, R.C., Adekile, D., MacDonald, A. Baumann, E., 2009. Cost effective boreholes in subSaharan Africa. In: Water, sanitation and hygiene: Sustainable development and multisectorial approaches. Proc. of the $34^{\text {th }}$ WEDC International Conference, Addis Ababa, Ethiopia.

Davis, R.W., 1969. Groundwater, gravity and Rift Valleys in Malawi. Ground Water 7(2) 34-36. https://doi.org/10.1111/i.1745-6584.1969.tb01275.x

Eastoe, C.J., 2016. Stable chlorine isotopes in arid non-marine basins: Instances and possible fractionation mechanisms. Applied Geochemistry 74, 1-12. https://doi.org/10.1016/j.apgeochem.2016.08.015

EED Advisory, 2018. Evaluation of the sustainability of solar powered water supply in Kenya. EED Advisory Ltd, Nairobi. http://www.eedadvisory.com/

Foster, S. S. D., Chilton, P. J., 2003. Groundwater: the processes and global significance of aquifer degradation. Philos. T. Roy. Soc. B, 358(1440), 1957-72. http://dx.doi.org/10.1098/rstb.2003.1380

Foster, S., Pulido-Bosch, A., Vallejos, Á. Luis Molina, L., Llop, A., MacDonald, A.M., 2018 Hydrogeol. J. (2018). Impact of irrigated agriculture on groundwater-recharge salinity: a major sustainability concern in semi-arid regions. Hydrogeol. J (2018) https://doi.org/10.1007/s10040-018-1830-2

Freeze, R.A., Cherry, J.A. 1979. Groundwater. Prentice Hall, Engle Wood Cliffs.

Garduño, H., van Steenbergen F., Foster, S. 2010. Stakeholder participation in groundwater management: enabling and nurturing engagement. GW-MATe Briefing Note Series 6. FAO-UN (Rome). World Bank, Washington, DC. http://siteresources.worldbank.org/EXTWAT/Resources/4602122-210186362590/GWM Briefing 6.pdf

Government of Malawi, 2016a. Ministry of Agriculture, Irrigation and Water Development: Standard Operating Procedure GW07/2012 Nov 2016: Drilling and construction of production boreholes.

Government of Malawi, 2016b. Ministry of Agriculture, Irrigation and Water Development: Technical Manual GW08 Nov 2016: Water wells and groundwater monitoring systems.

Greene, R., Timms, W., Rengasamy, P., Arshad, M. and Cresswell, R., 2016. Soil and aquifer salinization: Toward an integrated approach for salinity management of groundwater. In: Integrated Groundwater Management, 377-412. Springer International Publishing. https://doi.org/10.1007/978-3-319-23576-9 15 
Habgood, F., 1963. The geology of the country west of the Shire River between Chikwawa and Chiromo. Zomba: Ministry of Forestry and Natural Resources, Geological Survey Department. https://www.bgs.ac.uk/sadc/fulldetails.cfm?id=MW1152

Howard, G., Calow, R., MacDonald, A., Bartram, J., 2016. Climate change and water and sanitation: likely impacts and emerging trends for action. Ann. Rev. Environ. Resour., 41, 253276. https://doi.org/10.1146/annurev-environ-110615-085856

Huang, J., Prochazka, M.J., Triantafilis, J., 2016. Irrigation salinity hazard assessment and risk mapping in the lower Macintyre Valley, Australia. Sci. Tot. Environ., 551-552, 460-473. https://doi.org/10.1016/j.scitotenv.2016.01.200

Hutchings, P., Franceys, R., Smits, S., Mekala, S., 2017. Community Management of Rural Water Supply: Case Studies of Success from India (1 ${ }^{\text {st }} \mathrm{Ed}$.). Routledge Publ., 238 pp. https://www.crcpress.com/Community-Management-of-Rural-Water-Supply-Case-Studies-ofSuccess-from/Hutchings-Franceys-Smits-Mekala/p/book/9781138232075

Hutchings, P., Chan, M.Y., Cuadrado, L., Ezbakhe, F., Mesa, B., Tamekawa, C., Franceys, R., 2015. A systematic review of success factors in the community management of rural water supplies over the past 30 years. Water Policy, 17(5), 963-983. https://doi.org/10.2166/wp.2015.128

Ibrahim, M.P. and Alex, R.S., 2008. The impact of changing environmental conditions on vulnerable communities in the Shire Valley, Southern Malawi. In The Future of Drylands (pp. 545-559). Springer, Dordrecht. https://doi.org/10.1007/978-1-4020-6970-3 49

JICA (Japan International Cooperation Agency), 2018. Preparatory survey for the project for improvement of groundwater development and non-revenue water reduction in Malawi. Final Report for the Government of Malawi.

JMP report (2014): progress on drinking water and sanitation. World Health Organisation, Geneva. Joint Monitoring Programme (JMP) WHO/UNICEF. Available at: http://www.who.int/water sanitation health/publications/imp-report-2014/en/

Joshua, M.K., Ngongondo, C., Monjerezi, M., Chipungu, F., Liwenga, E., Majule, A.E., Stathers, T. and Lamboll, R., 2016. Climate change in semi-arid Malawi: Perceptions, adaptation strategies and water governance. Jàmbá: Journal of Disaster Risk Studies, 8(3), 1-10. https://doi.org/10.4102/jamba.v8i3.255

Liu, Y., Jin, M., Wang, J., 2018. Insights into groundwater salinization from hydrogeochemical and isotopic evidence in an arid inland basin. Hydrological Processes, 32(20), 3108-3127. https://doi.org/10.1002/hyp.13243

Lobell, D.B., Burke, M.B., Tebaldi, C., Mastrandrea, M.D., Falcon, W.P. and Naylor, R.L., 2008. Prioritizing climate change adaptation needs for food security in 2030. Science, 319(5863), 607-610. https://doi.org/10.1126/science.1152339 
Lockwood Survey Cooperation, 1970. Lower Shire Valley - Landforms, soils land classification. Food and Agricultural Organisation (FAO).

Macdonald, A.M., Bonsor, H.C., O'Dochartaigh, B.E., Taylor, R.G., 2012. Quantitative maps of groundwater resources in Africa. Environ. Res. Lett., 7(2), 024009. http://dx.doi.org/10.1088/1748-9326/7/2/024009

Macdonald, A.M., Calow, R.C., 2009. Developing groundwater for secure rural water supplies in Africa. Desalination, 248(1-3), 546-556. http://dx.doi.org/10.1016/j.desal.2008.05.100

Malawi Standards (MS), 2005. Standard for water delivered from Boreholes and Protected

Shallow Wells (MS733:2005).

Malawi Standards (MS), 2013. Drinking water specification (second edition) for treated drinking tap water (MS 214:2013).

Mannix, N., Norrie, J., Paterson, F., Nhlema, M., Mleta, P., Nkhata, M., Wanangwa, G., Kumwenda, S., Clarke, D., Kalin, R.M., 2018. Making the case for improved planning, construction and testing of water supply infrastructure in Malawi. In: Transformation towards sustainable and resilient WASH services, Proc. $41^{\text {st }}$ WEDC International Conference, Egerton University, Nakuru, Kenya, 2018.

Maoulidi, M., 2012. Water and sanitation needs assessment for Blantyre City, Malawi. MCI (Millennium Cities Initiative, Earth Institute, Columbia University) Social Sector, Working Paper Series, No. 27/2012, Columbia University Academic Commons, http://dx.doi.org/10.7916/D8D7997F (accessed 23/03/2018).

Mapoma, H.W.T., Xie, X., 2014. Basement and alluvial aquifers of Malawi: An overview of groundwater quality and policies. Afr. J. Environ. Sci. Technol., 8(3), 190-202. http://dx.doi.org/10.5897/AJEST2013.1639

Miller, A., Nhlema, M., Kumwenda, S., Mbalame, E., Uka, Z., Feighery, J., Kalin, R., 2018. Evolving water-point mapping to strategic decision making in rural Malawi. In: Transformation towards sustainable and resilient WASH services. Proc. $41^{\text {st }}$ WEDC International Conference, Egerton University, Nakuru, Kenya, 2018.

Minitab Inc., 2017. Minitab 17 Statistical Software. www.minitab.com (Accessed 24/06/2017)

MoAIWD (Ministry of Agriculture, Irrigation and Water Development) 2017a. National Water Resources Master Plan, Main Report - Existing Situation. Lilongwe, Malawi.

MoAIWD (Ministry of Agriculture, Irrigation and Water Development), 2017b. Shire Valley Irrigation project. Environmental and Social Management Plan for Phase 1. http://documents.worldbank.org/curated/en/271121495837484038/pdf/SFG3386-REVISEDREPLACEMENT-EA-P158805-PUBLIC-Disclosed-8-8-2017.pdf

MoAIWD (Ministry of Agriculture, Irrigation and Water Development), 2016a. State of the basin report for Shire River Basin: SRBMP - Sub-component A1: Development of a Basin Planning Framework, June 2016. http://www.shirebasin.mw/index.php?option=com joomdoc\&task=document.download\&pat h=State\%20of\%20the\%20Basin\%20Report.pdf\&Itemid=559 
MoAIWD (Ministry of Agriculture, Irrigation and Water Development), 2016b. Irrigation and cash crops for a better life. The Shire Valley Irrigation Project (SVIP). http://www.shirebasin.mw/index.php?option=com sppagebuilder\&view=page\&id=22\&Itemid $=518$

Monjerezi, M., 2012. Groundwater Salinity in lower Shire River valley (Malawi). Doctoral dissertation, PhD thesis, University of Oslo. http://www.mn.uio.no/kjemi/english/research/groups/environmental-science/environmentalchemistry/previous-phd-thesis/PhD thesis monjerezi.pdf

Monjerezi, M., Vogt, R.D., Aagaard, P., Saka, J.D.K., 2011a. Hydro-geochemical processes in an area with saline groundwater in lower Shire River valley, Malawi: An integrated application of hierarchical cluster and principal component analyses. Applied Geochemistry. 26, 1399-1413. http://dx.doi.org/10.1016/j.apgeochem.2011.05.013

Monjerezi, M., Vogt, R.D., Aagaard, P., Saka, J.D.K., 2012. The hydro-geochemistry of groundwater resources in an area with prevailing saline groundwater, lower Shire Valley, Malawi. J. Afr. Earth Sci., 68, 67-81. http://dx.doi.org/10.1016/i.jafrearsci.2012.03.012

Monjerezi, M., Vogt, R.D., Aagaard, P., Saka, J.D.K., 2011b. Using $\delta^{87} \mathrm{Sr} / \delta^{86} \mathrm{Sr}, \delta^{18} \mathrm{O}$ and $\delta^{2} \mathrm{H}$ isotope data along with major chemistry composition to assess groundwater salinization in lower Shire River Valley, Malawi. Appl. Geochem., 26, 2201-14. http://dx.doi.org/10.1016/j.apgeochem.2011.08.003

Monjerezi, M., Ngongondo, C., 2012. Quality of groundwater resources in Chikhwawa, Lower Shire Valley, Malawi. Water Qual. Exp. Health. 4, 39-53. http://dx.doi.org/10.1007/s12403$\underline{012-0064-0}$

Muir, A., Stephen, I., 1957. The superficial deposits of the Lower Shire Valley, Nyasaland. Geol. Min. Res., 6, 391-406.

National Statistical Office of Malawi, 2008. 2008 Population and housing census - main report. http://www.nsomalawi.mw/index.php?option=com_content\&view=article\&id=106\&ltemid=6

Ngongondo, C., Xu, C.Y., Gottschalk, L. and Alemaw, B., 2011. Evaluation of spatial and temporal characteristics of rainfall in Malawi: a case of data scarce region. Theoretical and applied climatology, 106(1-2), 79-93. https://doi.org/10.1007/s00704-011-0413-0

Pauwels, H., Aquilina, L., Negrel, P., Bour, O., Perrin, J., Ahmed, S., 2013. Groundwater salinization in hard-rock aquifers: impact of pumping and vertical transfers. Procedia Earth and Planetary Science 7, 660 - 664. https://doi.org/10.1016/i.proeps.2013.03.189

Pavelic, P., Giordano, M., Keraita, B., Ramesh, V, Rao, T., (Eds.). 2012. Groundwater availability and use in Sub-Saharan Africa: A review of 15 countries. Colombo, Sri Lanka: International Water Management Institute (IWMI). http://dx.doi.org/10.5337/2012.213

Peiris, M.J.N.R., 2009. Does the stereotype fit? NGO/Government relations in Malawi. Master of Science in Management, School of Graduate Studies of the University of Lethbridge, Alberta. https://www.uleth.ca/dspace/bitstream/handle/10133/3231/peiris\%2C\%20mututantrige.pdf? sequence $=1 \&$ is Allowed $=y$ 
Pisinaras, V., Tsihrintzis, V.A., Petalas, C., Ouzounis, K., 2010. Soil salinization in the agricultural lands of Rhodope District, northeastern Greece. Environ. Monit. Assess. 166, 79-94. https://doi.org/10.1007/s10661-009-0986-6

Pitkin, S.E., Cherry, J.A., Ingleton, R.A., Broholm, M., 1999. Field demonstrations using the Waterloo Ground water profiler. Ground Water Monitoring \& Remediation, 19, 122-131. https://doi.org/10.1111/j.1745-6592.1999.tb00213.x

Polmanteer, R.T., Kalin, R.M., 2014. An assessment of needs for improving sustainable drilling practices and hydrogeological conceptual model of the Mwanza River Valley, Chapananga, Malawi. Climate Justice Fund Water Futures Programme Report, University of Strathclyde.

Rivett, M.O., Cuthbert, M.O., Gamble R., Connon, L.E., Pearson, A., Shepley, M.G., Davis, J., 2016. Highway deicing salt dynamic runoff to surface water and subsequent infiltration to groundwater during severe UK winters. Sci. Tot. Environ., 565, 324-338. http://dx.doi.org/10.1016/j.scitotenv.2016.04.095

Rivett, M.O., Halcrow, A.H., Schmalfuss, J., Stark, J.A., Truslove, J.P., Kumwenda, S., Harawa, K.A., Nhlema, M., Songola, C., Wanangwa, G.J., Miller, A.V.M., Kalin, R.M., 2018a. Local scale water-food nexus: Use of borehole-garden permaculture to realise the full potential of rural water supplies in Malawi. Journal of Environmental Management, 209, 354-370. https://doi.org/10.1016/i.jenvman.2017.12.029

Rivett, M.O., Miller, A.V.M., MacAllister, D.J., Fallas, A., Wanangwa, G.J., Mleta, P., Phiri, P., Mannix, N., Monjerezi, M., Kalin, R.M., 2018b. A conceptual model based framework for pragmatic groundwater-quality monitoring network design in the developing world: Application to the Chikwawa District, Malawi. Groundwater for Sustainable Development 6, 213-226. https://doi.org/10.1016/i.gsd.2018.01.005

Robins, N., Davis, J., Farr, D., 2013. Groundwater supply and demand from southern Africa's crystalline basement aquifer: evidence from Malawi. Hydrolgeol. J., 21, 905-917. http://dx.doi.org/10.1007/s10040-013-0956-5

Robinson, H., 2018. A hydrogeochemical assessment of the geothermal potential of Southern Malawi. MSc Hydrogeology thesis (unpublished), Department of Civil and Environmental Engineering, University of Strathclyde.

Salameh, E., Alraggad, M., Tarawneh, A., 2014. Natural salinity sources in the groundwaters of Jordan-Importance ofsustainable aquifer management. Chemie der Erde, 74, 735-747. https://doi.org/10.1016/i.chemer.2014.04.007

Seo, D.H., Pineda, S., Woo, Y.C., Xie, M., Murdock, A.T., Ang, E.Y.M., Jiao, Y., Park, M.J., Lim, S.I., Lawn, M., Borghi, F.F., Han, Z.J., Gray, S., Millar, G., Du, A., Shon, H.K., Ng, T.Y., Ostrikov, K., 2018. Anti-fouling graphene-based membranes for effective water desalination. Nature Communications, 9, 683(2018). https://doi.org/10.1038/s41467-018-02871-3

Smedley, P., 2004. Groundwater quality: Malawi. British Geological Survey, 6pp. 
Smith-Carington, A.K., Chilton, P.J., 1983. Groundwater Resources of Malawi. Overseas Development Administration Institute of Geological Sciences. http://resources.bgs.ac.uk/sadcreports/malawi1983smithcarringtonmalawigwresources.pdf

Smout, I., 1999. Water and NGOs - Proceedings of an ODA workshop. Water, Engineering and Development Centre (WEDC), University of Loughborough, UK. https://wedcknowledge.Iboro.ac.uk/resources/books/Water_and_NGOs_-_Complete.pdf

Sutcliffe, C., Dougill, A.J. and Quinn, C.H., 2016. Evidence and perceptions of rainfall change in Malawi: Do maize cultivar choices enhance climate change adaptation in sub-Saharan Africa? Regional Environmental Change, 16(4), 1215-24. https://doi.org/10.1007/s10113-015-0842-x

Talukder, M.R.R., Rutherford, S., Phung, D., Islam, M.Z., Chu, C., 2016. The effect of drinking water salinity on blood pressure in young adults of coastal Bangladesh. Environmental Pollution 214, 248-254. https://doi.org/10.1016/j.envpol.2016.03.074

Tan, Z., Chen, S., Peng, X., Zhang, L., Gao, C., 2018. Polyamide membranes with nanoscale Turing structures for water purification. Science, 360(6388), 518-521.

https://doi.org/10.1126/science.aar6308

Upton, K., Ó Dochartaigh, B.É., Chunga, B. and Bellwood-Howard, I. 2018. Africa Groundwater Atlas: Hydrogeology of Malawi. British Geological Survey. http://earthwise.bgs.ac.uk/index.php/Hydrogeology of Malawi [accessed 23 March 2018]

Van Den Broek, M., Brown, J., 2015. Blueprint for breakdown? Community Based Management of rural groundwater in Uganda. Geoforum, 67, 51-63. http://doi.org/10.1016/i.geoforum.2015.10.009

Van Weert, F., Van der Gun, J. and Reckman, J., 2009. Global overview of saline groundwater occurrence and genesis. International Groundwater Resources Assessment Centre, Report GP2009-1. $\quad$ https://www.un-igrac.org/resource/global-overview-saline-groundwateroccurrence-and-genesis-0

Vineis, P., Chan, Q., Khan, A., 2011. Climate change impacts on water salinity and health. Journal of Epidemiology and Global Health, 1, 5- 10. https://doi.org/10.1016/j.jegh.2011.09.001

Wanda, E.M., Gulula, L.C. and Phiri, A., 2013. Hydrochemical assessment of groundwater used for irrigation in Rumphi and Karonga districts, Northern Malawi. Physics and Chemistry of the Earth, Parts A/B/C, 66, pp.51-59. https://doi.org/10.1016/i.pce.2013.09.001

Water Aid, 2013. Hand Pumps. Water Aid Technical Brief. www.wateraid.org/ng/ /media/Publications/Handpumps.pdf?la=en-NG

WHO (World Health Organisation), 2017. Guidelines for Drinking-Water Quality: Fourth Edition incorporating the First Addendum.

http://www.who.int/water sanitation health/publications/drinking-water-quality-guidelines4-including-1st-addendum/en/ (Accessed 19/02/2018). 
WRA (Water Resources Act), 2013. (No. 2 of 2013). An Act to provide for the management, conservation, use and control of water resources; for the acquisition and regulation of rights to use water; and for matters connected therewith or incidental thereto.

https://www.ecolex.org/details/legislation/water-resources-act-2013-no-2-of-2013-lexfaoc167598/ (accessed 05/09/2018)

Xue, J., Huo, Z., Wang, F., Kang, S., Huang, G., 2018. Untangling the effects of shallow groundwater and deficit irrigation on irrigation water productivity in arid region: New conceptual model. Sci. Tot. Environ., 619-620,1170-1182. https://doi.org/10.1016/j.scitotenv.2017.11.145 


\section{Supplementary Material}

\section{Responding to salinity in a rural African alluvial valley aquifer system: to boldly go beyond the world of hand-pumped groundwater supply?}

Michael O. Rivett ${ }^{1, *}$, Laura Budimir ${ }^{1}$, Nicholas Mannix ${ }^{1}$, Alexandra V.M. Miller ${ }^{1}$, Marc Addison $^{1}$, Phideria Moyo ${ }^{2}$, Gift J. Wanangwa ${ }^{2}$, Owen L. Phiri ${ }^{2}$, Chrispine E. Songola ${ }^{3}$, Muthi Nhlema ${ }^{4}$, Mavuto A.S. Thomas ${ }^{5}$, Reid T. Polmanteer ${ }^{1,6}$, Amando Borge ${ }^{1}$, Robert M. Kalin ${ }^{1}$

${ }^{1}$ Department of Civil and Environmental Engineering, University of Strathclyde, Glasgow G1 1XJ, UK

${ }^{2}$ The Ministry of Agriculture, Irrigation and Water Development, Regional Irrigation and Water Development Office - South, Private Bag 13, Blantyre, Malawi

${ }^{3}$ District Water Development Office Chikwawa District Council, Private Bag 1, Chikwawa, Malawi

${ }^{4}$ BASEflow, Galaxy House, Blantyre, Malawi.

${ }^{5}$ Dowa District Health Office, P.O. Box 25, Dowa, Malawi (formerly Chikwawa District Health Office).

${ }^{6}$ Now at: HRS Water Consultants, Lakewood, CO 80215, USA

* Corresponding author at: Department of Civil and Environmental Engineering, University of Strathclyde, Glasgow G1 1XJ, UK.

E-mail address: Michael.Rivett@strath.ac.uk (M.O. Rivett). 
Box SM1.

\section{Water quality suitability for agricultural use - irrigation}

Assessing the suitability of groundwater for agricultural use is primarily considered herein to underpin irrigation that may be used from small-holder private gardens up to a large farm enterprise. It is also relevant to initiatives such as borehole garden permaculture (Rivett et al., 2018) where groundwater inadvertently spilt at water points is used to irrigate a community garden allowing revenue obtained from produce grown to be used to help sustainably finance water point maintenance. A number of quality parameters are important for assessing the appropriateness of water use for irrigation, including electrical conductivity (EC), total dissolved solids (TDS), sodium percentage (\% $\mathrm{Na}$ ), sodium adsorption ratio (SAR) and permeability index (PI) (Wanda et al., 2013). When considering irrigation, the concentration of sodium ions in water is a particularly important parameter to determine, as $\mathrm{Na}^{+}$acts to reduce soil permeability, which inhibits plant growth and adversely affects crop production (Oster et al., 2016). Therefore, to assess the suitability of groundwater in the study area of Ngabu for use in irrigation, the percentage Sodium ion, the sodium absorption ratio (SAR) and permeability index (PI) were calculated.

Water with sodium percentage values greater than $60 \%$ are considered unacceptable for irrigation (Talabi et al., 2017). The sodium percentage was calculated from (ion concentrations in $\mathrm{meq} / \mathrm{l})$ :

$$
\% N a=\frac{(N a+K) \times 100}{(C a+M g+N a+K)}
$$

The SAR indicates the degree of cation exchange taking place between $\mathrm{Na}, \mathrm{Ca}$, and $\mathrm{Mg}$ ions (Singh et al., 2015) and is significant as breakdown of soil structure may occur when $\mathrm{Na}$ ions replace $\mathrm{Ca}$ and $\mathrm{Mg}$ adsorbed on soil particles (Oster et al., 2016). Hydraulic properties of the soil alter causing it to become hard, compact and hydrophobic which can inhibit plant growth (Maimon et al., 2017). SAR was calculated based upon (U.S. Salinity Laboratory Staff, 1954):

$$
\mathrm{SAR}=\frac{\mathrm{Na}}{\sqrt{\frac{\mathrm{Ca}+\mathrm{Mg}}{2}}}(\mathrm{meq} / \mathrm{l})
$$

Saline water when used for irrigation may hence reduce soil permeability over time (Parimalarenganayaki and Elango, 2014). The Permeability Index (PI) (Doneen, 1964; Ramesh and Elango, 2012) may be used to determine the appropriateness of water for irrigation (concentrations in $\mathrm{meq} / \mathrm{l}$ ):

$$
P I=\frac{\mathrm{Na}+\sqrt{\mathrm{HCO}}}{\mathrm{Ca} \mathrm{Mg}+\mathrm{Na}} \times 100
$$




\section{Table SM1.}

Results of Tukey pairwise comparison of groundwater salinity (EC) and underlying geology, at the $95 \%$ confidence level. Note: groups sharing the same letter are not significantly different.

\begin{tabular}{lccc}
\hline \multicolumn{1}{c}{ Underlying Geology } & $N$ & $\mathrm{EC}(\mu \mathrm{S} / \mathrm{cm})$ & Significance group \\
\hline Unconsolidated deposits & 268 & 2874 & $\mathrm{~A}$ \\
Karoo basalt basement & 95 & 1263 & $\mathrm{~B}$ \\
Cretaceous Lupata Sandstone & 16 & 3435 & $\mathrm{~A}$ \\
\hline
\end{tabular}

Table SM2.

Results of Tukey pairwise comparison of groundwater salinity (EC) and soil type, at the 95\% confidence level. Note: groups sharing the same letter are not significantly different.

\begin{tabular}{lccc}
\hline \multicolumn{1}{c}{ Soil Type } & $n$ & $\mathrm{EC}(\mu \mathrm{S} / \mathrm{cm})$ & Significance group \\
\hline Lithomorphic Vertisols & 171 & 2730 & $\mathrm{~A}$ \\
Shallow Lithomorphic Vertisols/Lithosols & 22 & 1592 & $\mathrm{AB}$ \\
Topovertisols & 51 & 2951 & $\mathrm{~A}$ \\
Alluvial Calcimorphic soils and Grey-Brown Earths & 49 & 2648 & $\mathrm{AB}$ \\
Lithosols & 56 & 1431 & $\mathrm{~B}$ \\
Shallow Grey-Brown Earths & 38 & 3005 & $\mathrm{~A}$ \\
\hline
\end{tabular}

Table SM3.

Correlation matrix (Pearson's correlation coefficient) showing the relationship between groundwater salinity and proximity to nearest river and proximity to nearest fault.

\begin{tabular}{llc}
\hline & EC $(\mu \mathrm{S} / \mathrm{cm})$ & $\begin{array}{c}\text { TDS } \\
(\mathrm{mg} / \mathrm{l})\end{array}$ \\
\hline Distance to nearest river $(\mathrm{m})$ & $-0.273^{*}$ & $-0.289^{*}$ \\
Distance to nearest fault $(\mathrm{km})$ & $0.054^{\mathrm{ns}}$ & $0.086^{\mathrm{ns}}$ \\
\hline *significant at 99\% confidence level & \\
${ }^{\mathrm{ns}}$ Not significant &
\end{tabular}




\section{References for Supplementary Material}

Doneen, L.D., 1964. Notes on water quality in agriculture. Published as Water Science and Engineering Paper 4001, Department of Water, Science and Engineering, University of California, Davis.

Maimon, A., Gross, A. and Arye, G., 2017. Greywater-induced soil hydrophobicity. Chemosphere, 184, 1012-1019. https://doi.org/10.1016/i.chemosphere.2017.06.080

Oster, J., Sposito, G. and Smith, C., 2016. Accounting for potassium and magnesium in irrigation water quality assessment. California Agriculture, 70(2), 71-76. https://doi.org/10.3733/ca.v070n02p71

Parimala-Renganayaki, S. and Elango, L., 2014. Impact of recharge from a check dam on groundwater quality and assessment of suitability for drinking and irrigation purposes. Arabian Journal of Geosciences, 7(8), 3119-3129. https://doi.org/10.1007/s12517-013-0989-z

Ramesh, K. and Elango, L., 2012. Groundwater quality and its suitability for domestic and agricultural use in Tondiar river basin, Tamil Nadu, India. Environmental monitoring and assessment, 184(6), 3887-3899. https://doi.org/10.1007/s10661-011-2231-3

Rivett, M.O., Halcrow, A.H., Schmalfuss, J., Stark, J.A., Truslove, J.P., Kumwenda, S., Harawa, K.A., Nhlema, M., Songola, C., Wanangwa, G.J., Miller, A.V.M., Kalin, R.M., 2018. Local scale water-food nexus: Use of borehole-garden permaculture to realise the full potential of rural water supplies in Malawi. Journal of Environmental Management, 209, 354-370. https://doi.org/10.1016/j.jenvman.2017.12.029

Singh, S., Raju, N.J., Ramakrishna, C., 2015. Evaluation of groundwater quality and its suitability for domestic and irrigation use in parts of the Chandauli-Varanasi region, Uttar Pradesh, India. Journal of Water Resource and Protection, 7(7), 572-587. https://doi.org/10.4236/jwarp.2015.77046

Talabi, A.O., Afolagboye, L.O., Aturamu., A.O., Olofinlade, S.W., 2017. Suitability Evaluation of River

Owan Water for Irrigation. Journal of Environmental Science, Toxicology and Food Technology, 11(4), 74-80. www.iosrjournals.org/iosr-jestft/papers/vol11-issue\%204/...1/L1104017480.pdf

U.S. Salinity Laboratory Staff, 1954. Diagnosis and improvement of saline and alkali soils (Handbook No. 60) L. A. Richards, Ed. U.S. Dept. of Agriculture, Washington, D.C., 160 pp.

Wanda, E.M., Gulula, L.C., Phiri, A., 2013. Hydrochemical assessment of groundwater used for irrigation in Rumphi and Karonga districts, Northern Malawi. Physics and Chemistry of the Earth, Parts A/B/C, 66, 51-59. https://doi.org/10.1016/i.pce.2013.09.001 